OPEN ACCESS

Edited by:

Paolo Bernardi,

University of Padua, Italy

Reviewed by:

Eric Fontaine,

Université Joseph Fourier, France

Aiit Divakaruni,

UCLA Health System, United States

${ }^{*}$ Correspondence:

Christos Chinopoulos

chinopoulos.christos@eok.sote.hu

Specialty section:

This article was submitted to

Mitochondrial Research

a section of the journal

Frontiers in Physiology

Received: 17 March 2020 Accepted: 02 November 2020 Published: 01 December 2020

Citation:

Chinopoulos C (2020) From

Glucose to Lactate and Transiting Intermediates Through Mitochondria,

Bypassing Pyruvate Kinase:

Considerations for Cells Exhibiting Dimeric PKM2 or Otherwise Inhibited

Kinase Activity.

Front. Physiol. 11:543564.

doi: 10.3389/fphys.2020.543564

\section{From Glucose to Lactate and Transiting Intermediates Through Mitochondria, Bypassing Pyruvate Kinase: Considerations for Cells Exhibiting Dimeric PKM2 or Otherwise Inhibited Kinase Activity}

\author{
Christos Chinopoulos* \\ Department of Medical Biochemistry, Semmelweis University, Budapest, Hungary
}

A metabolic hallmark of many cancers is the increase in glucose consumption coupled to excessive lactate production. Mindful that L-lactate originates only from pyruvate, the question arises as to how can this be sustained in those tissues where pyruvate kinase activity is reduced due to dimerization of PKM2 isoform or inhibited by oxidative/nitrosative stress, posttranslational modifications or mutations, all widely reported findings in the very same cells. Hereby 17 pathways connecting glucose to lactate bypassing pyruvate kinase are reviewed, some of which transit through the mitochondrial matrix. An additional 69 converging pathways leading to pyruvate and lactate, but not commencing from glucose, are also examined. The minor production of pyruvate and lactate by glutaminolysis is scrutinized separately. The present review aims to highlight the ways through which L-lactate can still be produced from pyruvate using carbon atoms originating from glucose or other substrates in cells with kinetically impaired pyruvate kinase and underscore the importance of mitochondria in cancer metabolism irrespective of oxidative phosphorylation.

Keywords: cancer, glycolysis, mitochondria, metabolomics, Warburg effect, oncometabolism, lactate dehydrogenase

\section{GLUCOSE AND LACTATE IN CANCER: BACKGROUND}

It is a well-known fact that most cancers exhibit increased rates in glucose consumption (Bose and Le, 2018). This is clinically exploited by following radionuclide-labeled glucose analogs for the purpose of tumor imaging in living human beings (Feng et al., 2019). The very same cancers are also known to be major lactate producers, which is important for their survival (de la Cruz-Lopez et al., 2019). The combination of an increased consumption of glucose with an increase in lactate output led to the assumption that cancers exhibit an increase in glycolysis; although this is true, serving the purpose of 
generating glycolytic metabolites which are diverted toward biosynthetic processes (DeBerardinis et al., 2008) and NADPH by the pentose phosphate pathway (Icard and Lincet, 2012), most tumors express a dimeric form of the M2 isoform of pyruvate kinase which has been reported to be much less active than that found in healthy cells; furthermore, numerous posttranslational modifications and mutations have been reported for this gene product, leading to a much reduced activity but still fueling cancer aggression (see section "Pyruvate Kinase"). Even more so, tumor cells with undetectable levels of pyruvate kinase still producing lactate can be found in vivo (Israelsen et al., 2013). On one hand, the decrease in pyruvate kinase activity is important for maintaining a metabolite "traffic jam," forcing upstream metabolites toward biosynthetic pathways; on the other hand, it points to a metabolic conundrum because L-lactate may only originate from pyruvate, a metabolite arising from phosphoenolpyruvate (PEP) through pyruvate kinase in glycolysis (see Figure 1). The purpose of this review is to highlight the pathways that can lead to pyruvate and lactate-even commencing from glucose-bypassing pyruvate kinase. This is important because (i) carbon-labeled atoms in glucose may appear in lactate without net ATP production from glycolysis and (ii) hints on the possibility that other pathways leading to pyruvate/lactate could be crucial for cancer cell survival that are perhaps amenable to pharmacological and/or genetic manipulation. The list of pathways appearing below has been assembled by mining the following databases: Kyoto Encyclopedia of Genes and Genomes ${ }^{1}$ (Kanehisa and Goto, 2000), BRaunschweig ENzyme Database ${ }^{2}$ (Jeske et al., 2019), Metabolic Atlas ${ }^{3}$ (Robinson et al., 2020), Biochemical, Genetic, and Genomic knowledge base ${ }^{4}$ (King et al., 2016), MetaNet $X^{5}$ (Moretti et al., 2016), Human Metabolome Database $^{6}$ (Wishart et al., 2018), and Virtual Metabolic Human ${ }^{7}$ (Noronha et al., 2019).

\section{PYRUVATE KINASE}

Pyruvate kinase generates ATP at the "substrate level" in the absence of oxygen by catalyzing the dephosphorylation of PEP to pyruvate (see Figure 1). There are four isoforms denoted as L, R, M1, and M2. For details regarding kinetic properties, tissue distribution, and regulation, the reader is referred to the review by Israelsen and Vander Heiden (2015). In the present review, the PKM2 isoform will be specifically examined; for a more thorough evaluation, the reader is referred to Li et al. $(2014,2018)$, Wong et al. (2015); Yang and Lu (2015), Dayton et al. (2016b), Hsu and Hung (2018), and Alquraishi et al. (2019). The non-enzymatic functions of PKM2 are examined elsewhere (Hoshino et al., 2007;

\footnotetext{
${ }^{1}$ https://www.genome.jp/kegg/

${ }^{2}$ www.brenda-enzymes.org

${ }^{3}$ https://www.metabolicatlas.org/

${ }^{4}$ http://bigg.ucsd.edu/

${ }^{5} \mathrm{http}: / /$ www.metanetx.org/

${ }^{6}$ www.hmdb.ca

${ }^{7}$ https://www.vmh.life/
}

Stetak et al., 2007; Luo et al., 2011; Yang et al., 2012; Yang and Lu, 2013).

Basically, PKM2 exhibits lower enzymatic activity compared to that by PKM1 (Yamada and Noguchi, 1999) and is allosterically regulated by fructose-1,6-bisphosphate (FBP); it exists either as a dimer with low affinity for PEP or as an FBP-bound tetramer with high affinity for PEP (Mazurek et al., 2005; Zhang et al., 2019). Although PKM2 has been branded as "the predominant isoform in cancer cells" (Altenberg and Greulich, 2004; Mazurek et al., 2005), further scrutiny in 25 human malignant cancers, six benign oncocytomas, tissue-matched controls, and several cell lines showed that "PKM2 dominance was not a result of a change in isoform expression, since PKM2 was also the predominant PKM isoform in matched control tissues." Therefore, a switch from PKM1 to PKM2 isoform expression during malignant transformation may not be taking place, as previously postulated (Christofk et al., 2008). Mindful of the controversy surrounding the proposed functions of PKM2 (Hosios et al., 2015; Harris and Fenton, 2019), the group of Vander Heiden characterized the effects of cancer-associated PKM2 mutations on enzyme kinetics and allosteric regulation and reported that a decrease in PKM2 activity supports the rapid proliferation of cells (Liu V. M. et al., 2020). This is in line with earlier reports showing that a decrease in PKM2 activity due to posttranslational modifications (Lv et al., 2011) or inhibition by oxidative stress (Anastasiou et al., 2011) promotes tumor growth (Prakasam et al., 2018). Alternatively, exposure to small molecule PKM2 activators or expression of the constitutively active PKM1 thwarts cancer cell proliferation (Anastasiou et al., 2012). Finally, it has been also shown that PKM2 is not even required for the growth of many cancers (Cortes-Cros et al., 2013; Israelsen et al., 2013; Wang et al., 2014; Lunt et al., 2015; Dayton et al., 2016a, 2018; Lau et al., 2017; Tech et al., 2017; Hillis et al., 2018). In aggregate, the consensus seems to be that the lower the pyruvate kinase activity, the greater the stimulation of tumor growth. As discussed in the section below entitled "Evidence Showing That Pyruvate Kinase Inhibition Does Not Lead to a Proportional Decrease in Pyruvate/Lactate Formation," even those cells exhibiting low-or even undetectable-pyruvate kinase activity still produce lactate, which begs the question: where does this lactate come from?

\section{EVIDENCE SHOWING THAT PYRUVATE KINASE INHIBITION DOES NOT LEAD TO A PROPORTIONAL DECREASE IN PYRUVATE/LACTATE FORMATION}

In Cortes-Cros et al. (2013), it was shown that knockdown of both PKM1 and PKM2 (PKM2 knockdown was on the order of $>95 \%$ ) leading to an approximately fivefold decrease in overall pyruvate kinase activity yielded only a $\sim 50 \%$ decrease in the appearance of ${ }^{13} \mathrm{C}$ originating from glucose to lactate.

In Chaneton et al. (2012), silencing of both PKM1 and PKM2 to an extent greater than $90 \%$ led to only a $\sim 30 \%$ decrease in pyruvate and lactate production, while PEP concentration increased by $100 \%$. 


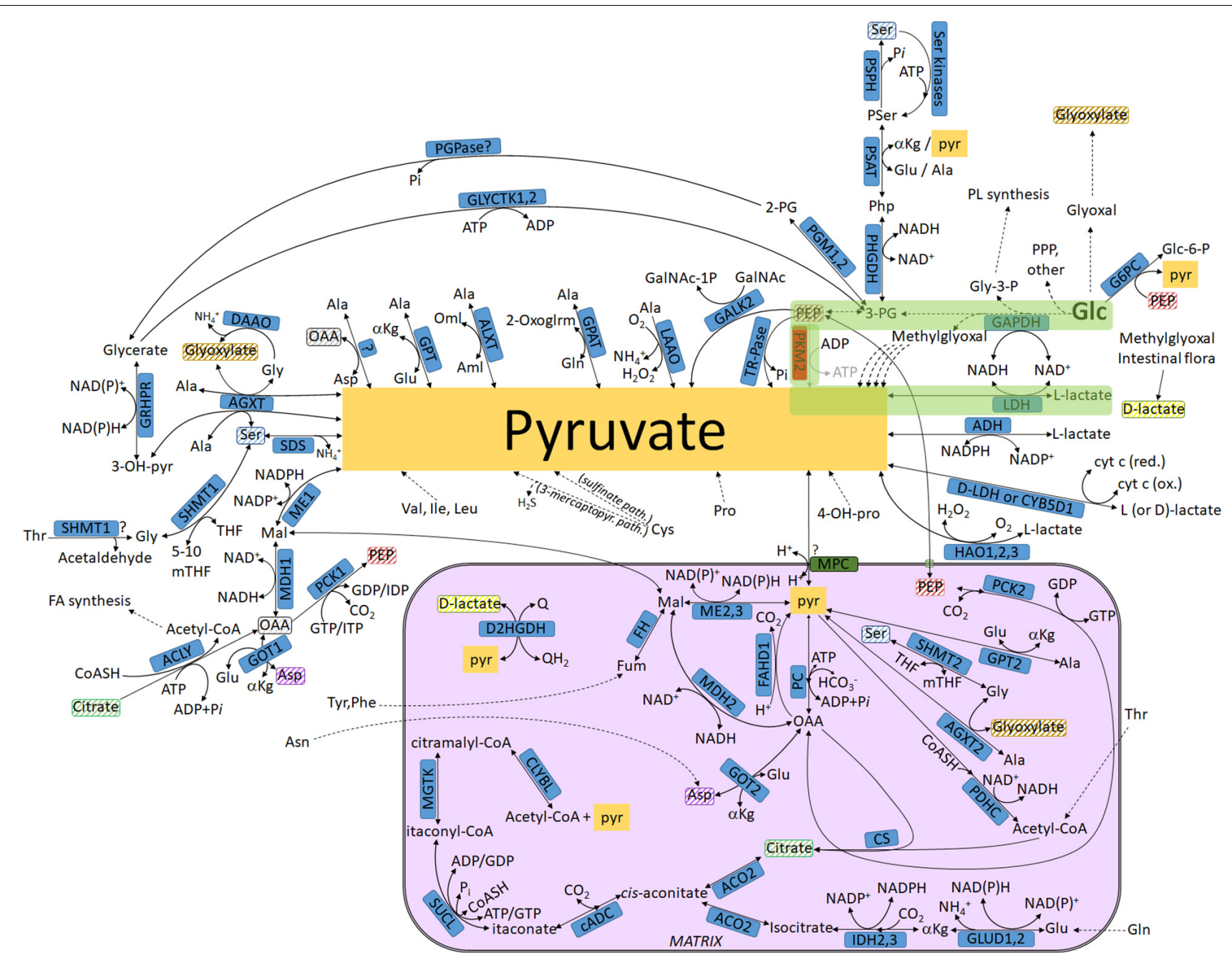

FIGURE 1 | Biochemical pathways connecting glucose or other metabolites to pyruvate and L- or D-lactate. The box in magenta represents a mitochondrion. Glycolysis is highlighted in green. Metabolites found both inside and outside the mitochondria that are not connected with an arrow are highlighted in matching striped colors (to avoid arrow clutter). For abbreviations, see Table 1.

In Vander Heiden et al. (2010), it was shown that cancer cell lysates expressing no pyruvate kinase activity produced $50 \%$ of pyruvate from PEP compared with the total cell lysates. Although in this work it was postulated that phosphate from PEP is transferred to the catalytic histidine on human PGAM1, this claim was subsequently rejected by the same authors, attributing their earlier findings to contaminating ATP-dependent protein kinases (Hosios et al., 2015).

In all of the abovementioned studies, it was assumed that, in view of severely diminished pyruvate kinase activity, pyruvate and lactate production is attributed to carbon sources other than glucose. Indeed $\mathrm{Yu}$ et al. (2019), determined that, in pancreatic ductal adenocarcinoma cells with PKM1 and PKM2 knockdown, cysteine catabolism generated $\sim 20 \%$ of intracellular pyruvate. The purpose of the present review is to not only outline these pathways but also show additional ways for obtaining ${ }^{13} \mathrm{C}$ labeling in pyruvate or lactate originating from glucose; furthermore, since some of these pathways involve intermediates that transit through the matrix, the role of the mitochondria is emphasized, which is unrelated to the concept of oxidative phosphorylation.

\section{PATHWAYS LEADING TO PYRUVATE COMMENCING FROM GLUCOSE: INTERMEDIATES NOT TRANSITING THROUGH THE MITOCHONDRIA}

The pathways shown in this section refer to Figure 2 (lavender arrows). Multiple arrows imply multiple biochemical steps.

(1) Glc + PEP $\rightarrow$ Glc-6-P + pyruvate: This reaction is catalyzed by glucose-6-phosphatase (G6PC) (Nordlie, 1974; Colilla et al., 1975) (for abbreviations, see Table 1). In humans, G6PC expression was reported to be elevated in GBM when compared with normal brain (Abbadi et al., 2014), 


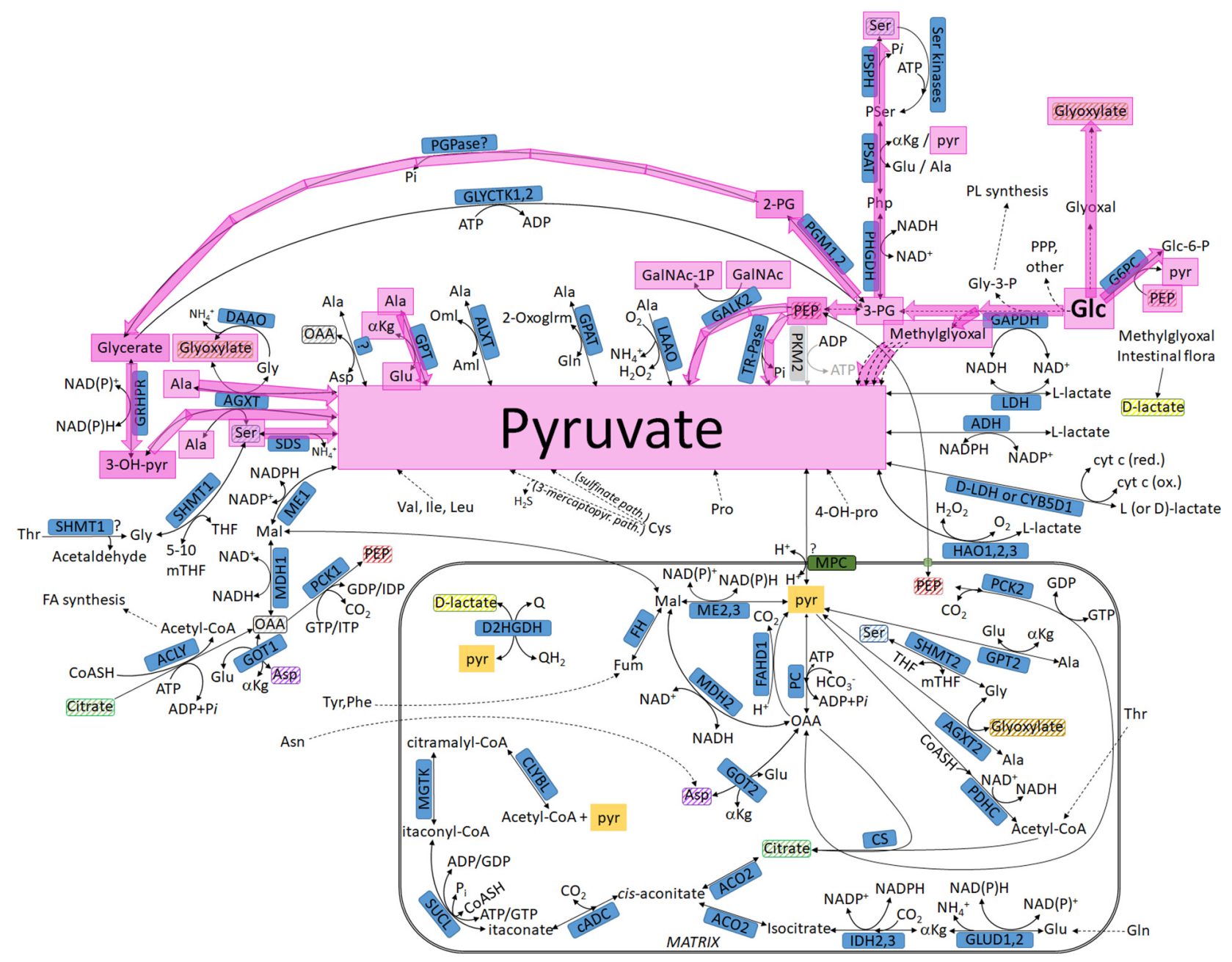

FIGURE 2 | Pathways leading to pyruvate commencing from glucose, highlighted in lavender: intermediates not transiting through the mitochondria. For abbreviations, see Table 1.

while in rodent hepatomas it was found to be decreased (Weber and Cantero, 1955).

(2) Glc $\rightarrow \rightarrow \rightarrow$ methylglyoxal $\rightarrow \rightarrow \rightarrow$ pyruvate: This may occur through four different routes involving aldehyde dehydrogenase 9, zinc binding alcohol dehydrogenase domain containing two [more recently renamed to prostaglandin reductase 3 (Yu et al., 2013)] and at least two oxoaldehyde dehydrogenases; for details, see Vander Jagt and Hunsaker (2003). Methylglyoxal has been reported to trigger metastasis in breast, anaplastic thyroid, and colorectal cancer (Chiavarina et al., 2017; Antognelli et al., 2019; Nokin et al., 2019).

(3) Glc $\rightarrow \rightarrow \rightarrow$ PEP $\rightarrow$ pyruvate: the terminal reaction is catalyzed by tartrate-resistant acid phosphatases (TRAP), the molecular identity of which remained unknown well after their biochemical characterization (Helwig et al., 1978; Chen and Chen, 1988; Hayman et al., 1989); they are most likely substantiated by a metalloprotein enzyme with the ability to catalyze the hydrolysis of orthophosphate monoesters under acidic conditions (Bull et al., 2002). The expression of this enzyme
(TRAP) is a marker of bone disease in cancer patients (Nguyen et al., 1991; Koizumi and Ogata, 2002; Mose et al., 2003; Terpos et al., 2003; Chao et al., 2005).

(4) Glc $\rightarrow \rightarrow \rightarrow$ PEP; PEP + GalNAc $\rightarrow$ GalNAc$1 \mathrm{P}+$ pyruvate: Terminal reaction catalyzed by $\mathrm{N}$-acetylgalactosamine kinase isoforms 1 or 2 (Pastuszak et al., 1996). These enzymes are implicated in many signaling pathways inherent to carcinogenesis (Zeidan and Hart, 2010).

(5) Glc $\rightarrow \rightarrow \rightarrow$ 3-PG $\rightarrow$ 2-PG (by phosphoglucomutase 1 or 2) $\rightarrow$ glycerate [probably through 2-phosphoglyceric acid phosphatase (Baranowski et al., 1968)] $\rightarrow$ 3-OH-pyr [by glyoxylate reductase (Mdluli et al., 2005)]; 3-OH-pyr + Ala (or glyoxylate) $\rightarrow$ Gly + pyruvate (or Ser): the terminal reaction is catalyzed by alanine-glyoxylate aminotransferase (Danpure et al., 2003). The mitochondrial isoform of the latter enzyme (alanine-glyoxylate aminotransferase isoform 2, AGXT2) has been reported to form glycine and pyruvate from alanine and glyoxylate; this reaction has been confirmed in normal tissues (Holmes and Assimos, 1998) and HepG2 cancer cells 
TABLE 1 | Abbreviations.

\begin{tabular}{|c|c|}
\hline 2-Oxoglrm & 2-oxoglutaramate (a-ketoglutaramate) \\
\hline 2-PG & 2-Phosphoglycerate \\
\hline 3-OH-pyr & 3-hydroxypyruvate \\
\hline 3-PG & 3-Phosphoglycerate \\
\hline 4-OH-proline & 4-hydroxyproline \\
\hline 5-10 mTHF & 5-10 methylene-Tetrahydrofolate \\
\hline ACLY & ATP Citrate Lyase \\
\hline ACO & Aconitase \\
\hline $\mathrm{ADH}$ & Alcohol Dehydrogenase \\
\hline AGXT & Alanine-glyoxylate Aminotransferase \\
\hline aKG & a-ketoglutarate \\
\hline Ala & Alanine \\
\hline ALXT & Alanine-Ketomalonate Transaminase \\
\hline Aml & Aminomalonate \\
\hline Asn & Asparagine \\
\hline Asp & Aspartate \\
\hline CADC & cis-Aconitate Decarboxylase \\
\hline CLYBL & Citramalyl-CoA Lyase \\
\hline CS & Citrate Synthase \\
\hline CYB5D1 & Cytochrome B5 Domain-Containing Protein 1 \\
\hline Cys & Cysteine \\
\hline D2HGDH & D-2-Hydroxyglutarate Dehydrogenase \\
\hline DAAO & D-amino acid Oxidase \\
\hline D-LDH & D-Lactate Dehydrogenase \\
\hline FAHD & Acylpyruvase \\
\hline $\mathrm{FH}$ & Fumarate Hydratase \\
\hline Fum & Fumarate \\
\hline G6PC & Glucose 6 phosphatase \\
\hline GALK & $\mathrm{N}$-acetylgalactosamine Kinase \\
\hline GalNAc & N-Acetylgalactosamine \\
\hline GalNAc-1-P & N-Acetylgalactosamine-1-Phosphate \\
\hline GAPDH & Glyceraldehyde 3 Phosphate Dehydrogenase \\
\hline Glc & Glucose \\
\hline Glc-6-P & Glucose-6-phosphate \\
\hline Gln & Glutamine \\
\hline Glu & Glutamate \\
\hline GLUD & Glutamate Dehydrogenase \\
\hline Gly & Glycine \\
\hline Gly-3-P & Glyceraldehyde-3-Phosphate \\
\hline GLYCTK & Glycerate Kinase \\
\hline GOT & Aspartate Aminotransferase \\
\hline GPAT & Glutamine-Pyruvate Transaminase \\
\hline GPT & Alanine Aminotransferase \\
\hline GRHPR & Glyoxylate Reductase \\
\hline $\mathrm{HAO}$ & Hydroxyacid Oxidase \\
\hline $\mathrm{IDH}$ & Isocitrate Dehydrogenase \\
\hline lle & Isoleucine \\
\hline KGDHC & a-Ketoglutarate Dehydrogenase Complex \\
\hline LAAO & L-amino-acid Oxidase \\
\hline LDH & Lactate Dehydrogenase \\
\hline Leu & Leucine \\
\hline Mal & Malate \\
\hline $\mathrm{MDH}$ & Malate Dehydrogenase \\
\hline ME & Malic Enzyme \\
\hline MGTK & Methylglutaconase \\
\hline
\end{tabular}

(Continued)
TABLE 1 | Continued

\begin{tabular}{ll}
\hline MPC & Mitochondrial Pyruvate Carrier \\
mTHF & methyl-Tetrahydrofolate \\
OAA & Oxaloacetate \\
Oml & Oxomalonate \\
PCK & Phosphoenolpyruvate Carboxykinase \\
PCK & Pyruvate Carboxylase \\
PDHC & Pyruvate Dehydrogenase Complex \\
PEP & Phosphoenolpyruvate \\
PGM & Phosphoglucomutase \\
PGPase & 2-phosphoglyceric acid Phosphatase \\
Phe & Phenylalanine \\
PHGDH & Phosphoglycerate Dehydrogenase \\
Php & Phosphohydroxypyruvate \\
PKM2 & Pyruvate Kinase isoform M2 \\
PL & Phospholipids \\
PPP & Pentose Phosphate Pathway \\
PSAT & Phosphoserine Aminotransferase \\
Pser & Phosphoserine \\
PSPH & Phosphoserine Phosphatase \\
Pyr & Pyruvate \\
Q & Quinone \\
QH2 & Quinol \\
SDH & Succinate Dehydrogenase \\
SDS & Serine Dehydratase \\
Ser & Serine \\
SHMT & Serine Hydroxymethyltransferase \\
SUCL & Succinate-CoA Ligase \\
THF & Tetrahydrofolate \\
Thr & Threonine \\
TR-Pase & Tartrate-resistant acid Phosphatase \\
Tyr & Tyrosine \\
Val & Valine \\
\hline &
\end{tabular}

(Baker et al., 2004). The same reaction has been reported to take place in peroxisomes (Poore et al., 1997). On the other hand, loss of alanine-glyoxylate aminotransferase (AGXT) expression has been reported to accelerate the progression of hepatocellular carcinoma (Sun et al., 2019). A "futile cycle" may exist between 3-PG and glycerate through 2-phosphoglyceric acid phosphatase and glycerate kinase 1 and 2; glycerate kinase 2 is also found in the mitochondria (Guo et al., 2006).

(6) Glc $\rightarrow \rightarrow \rightarrow$ 3-PG $\rightarrow$ phosphohydroxypyruvate (Php), catalyzed by phosphoglycerate dehydrogenase; $\mathrm{Php}+\mathrm{Ala} \rightarrow$ phosphoserine (Pser) + pyruvate, catalyzed by phosphoserine aminotransferase (PSAT) (Hirsch and Greenberg, 1967): PSAT overexpression is associated with increased tumorigenicity in human esophageal squamous cell carcinoma (Liu et al., 2016) and colon carcinomas (Yoon et al., 2015) and a poor outcome on tamoxifen therapy in recurrent breast cancer (De Marchi et al., 2017); conversely, its selective loss suppresses migration, invasion, and experimental metastasis in triple negative breast cancer (Metcalf et al., 2020).

(7) Glc $\rightarrow \rightarrow \rightarrow 3-\mathrm{PG} \rightarrow \mathrm{Php}$ (catalyzed by phosphoglycerate dehydrogenase); Php + Ala (or Glu) $\rightarrow$ Pser + pyruvate (or $\rightarrow \mathrm{Kg}$ ); the latter reaction is catalyzed by phosphoserine 
aminotransferase; Pser $\rightarrow$ Ser $\rightarrow$ pyruvate, catalyzed by serine dehydratase (Ogawa et al., 2006) or serine dehydratase-like (SDSL) (Ogawa et al., 2006). Notably, SDS was reported to be absent from human colon carcinomas (Snell et al., 1988).

(8) Glc $\rightarrow \rightarrow \rightarrow$ Glyoxal $\rightarrow \rightarrow \rightarrow$ glyoxylate (Lange et al., 2012); glyoxylate + 3-OH-pyr (or Ala) $\rightarrow$ Gly + pyruvate (or Ser): the terminal reaction is catalyzed by AGXT (for considerations related to cancer, see pathway no. 5).

(9) Glc $\rightarrow \rightarrow \rightarrow 3$-PG $\rightarrow$ Php (catalyzed by phosphoglycerate dehydrogenase); Php + Glu $\rightarrow$ Pser $+\rightarrow \mathrm{Kg}$; latter reaction catalyzed by phosphoserine aminotransferase; $\rightarrow \mathrm{Kg}+\mathrm{Ala} \rightarrow$ Glu + pyruvate, catalyzed by alanine aminotransferase (GPT; for considerations related to cancer, see pathway no. 6).

\section{PATHWAYS LEADING TO PYRUVATE COMMENCING FROM GLUCOSE: INTERMEDIATES TRANSITING THROUGH THE MITOCHONDRIA}

These pathways depend on one or more of three critical parameters: (1) glyoxylate entry into the mitochondria, (2) reversibility of the matrix phosphoenolpyruvate carboxykinase (PCK2), and (3) reversibility of the mitochondrial pyruvate carrier (MPC). Regarding glyoxylate, I was unable to find information on its transport across the inner mitochondrial membrane; however, it is known that it can be processed by the matrix-localized AGXT2 (Kakimoto et al., 1969). PCK2 expression and activity level are critical for many cancer types: in tumor-initiating enriched prostate cancer cell clones, PCK2 was overexpressed, and this correlated with more aggressive tumors and lower survival rates (Zhao et al., 2017); in lung cancer cell lines and in non-small cell lung cancer samples, PCK2 expression and activity were enhanced under low-glucose conditions (Leithner et al., 2015); finally, it was reported that PCK2 is required for glucose-independent cancer cell proliferation and tumor growth in vivo (Vincent et al., 2015). Regarding PCK2 reversibility, the enzyme has been shown to operate in the reaction toward OAA synthesis in mitochondria from rabbit liver (Carlsen et al., 1988), pigeon and rat liver (Wiese et al., 1996), guinea pig liver (Garber and Ballard, 1970; Garber and Salganicoff, 1973), rabbit enterocytes (Wuensch and Ray, 1997), chicken liver (Hebda and Nowak, 1982; Makinen and Nowak, 1983; Wilson et al., 1983; Erecinska and Wilson, 1984), and bullfrog liver (Goto et al., 1980). However, in Vincent et al. (2015), it was shown that a fraction of pyruvate originated from glutamine from PEP through PCK2. With respect to the reversibility of the MPC, this is a working hypothesis because there are no data showing pyruvate release from normally polarized mitochondria. Nevertheless, this is not a far-fetched hypothesis: succinate and other metabolites are effluxed from the mitochondria for non-metabolic roles against a hyperpolarized membrane potential (Mills et al., 2016), demonstrating that this is possible under appropriate conditions. It may be also relevant that pyruvate catabolism through the pyruvate dehydrogenase complex is associated with suppression of tumor growth in vitro and in vivo (Michelakis et al., 2008); relevant to this, genes coding for both the pyruvate dehydrogenase complex and pyruvate carboxylase in certain cancers are usually downregulated (Yuen et al., 2016); furthermore, pyruvate is found in blood plasma, urine, and cerebrospinal fluid, and its presence there is not associated with damage of plasma membranes. Of course, this does not mean that extracellular pyruvate originated from the mitochondria, but it indicates that it can cross the plasma membrane through monocarboxylate transporters, some of which are distributed both in plasma and in the inner mitochondrial membrane (Hussien and Brooks, 2011); indeed monocarboxylate transporter 1, which is one of the four known pyruvate transport mechanisms, was recently shown to export pyruvate from the cell (Hong et al., 2016); however, mitochondrial pyruvate export remains hypothetical especially in view of the fact that its exit is influenced by the membrane potential and $\rightarrow \mathrm{pH}$. It was also recently reported that loss of an MPC isoform prior to a tumorigenic stimulus doubled the frequency of adenoma formation and produced higher-grade tumors, and this was associated with a glycolytic metabolic phenotype and increased expression of stem cell markers (Bensard et al., 2020). Mindful of the above, these pathways are as shown in Figure 3 (yellow arrows).

(10) Glc $\rightarrow \rightarrow \rightarrow$ glyoxal $\rightarrow \rightarrow \rightarrow$ glyoxylate: Glyoxylate enters the mitochondria; glyoxylate + Ala $\rightarrow$ Gly + pyruvate through AGXT2. Pyruvate may exit the mitochondria through the MPC (for considerations related to cancer, see pathway no. 5).

(11) Glc $\rightarrow \rightarrow \rightarrow$ PEP which enters the mitochondria; PEP transport across the inner membrane of mammalian mitochondria has been demonstrated to occur by the tricarboxylate carrier by Robinson (1971) and the group of Soling et al. (1971) and Kleineke et al. (1973) and to a lesser extent by the adenine nucleotide carrier, shown by the Shug and Shrago (1973); Sul et al. (1976) and in Drahota et al. (1983) and reviewed in Passarella et al. (2003). The possibility of a $\mathrm{PEP} /$ pyruvate transporter has also been put forward (Satrustegui et al., 2007). More recently, PEP cycling via mitochondrial PEPCK evoking PEP transport across the inner mitochondrial membrane has also been demonstrated by the group of Kibbey (Stark et al., 2009); PEP $\rightarrow$ OAA by PCK2; OAA $\rightarrow$ pyruvate by reverse operation of PC. However, this is expected to be a very minor path. Pyruvate may exit the mitochondria through the MPC.

(12) Glc $\rightarrow \rightarrow \rightarrow$ PEP; PEP enters the mitochondria through the means outlined in pathway 11 . PEP $\rightarrow$ OAA by PCK2; OAA $\rightarrow$ pyruvate by FAHD1 (Pircher et al., 2011, 2015). FAHD1 also converts 3-acylpyruvate, acetylpyruvate, and fumarylpyruvate to pyruvate (Pircher et al., 2011). It is not known where acetylpyruvate comes from, but its existence is known since Krebs reported it (Krebs and Johnson, 1937). Pyruvate may exit the mitochondria through the MPC. FAHD1 depletion has been shown to induce premature senescence in human endothelial cells by inhibiting mitochondrial metabolism (Petit et al., 2017); however, this might be a double-edged sword since OXPHOS capacity has been inversely correlated with malignancy in several cell types (Zhou et al., 2003; Matoba et al., 2006; Hu et al., 2012; Hall et al., 2013; Bartesaghi et al., 2015; 


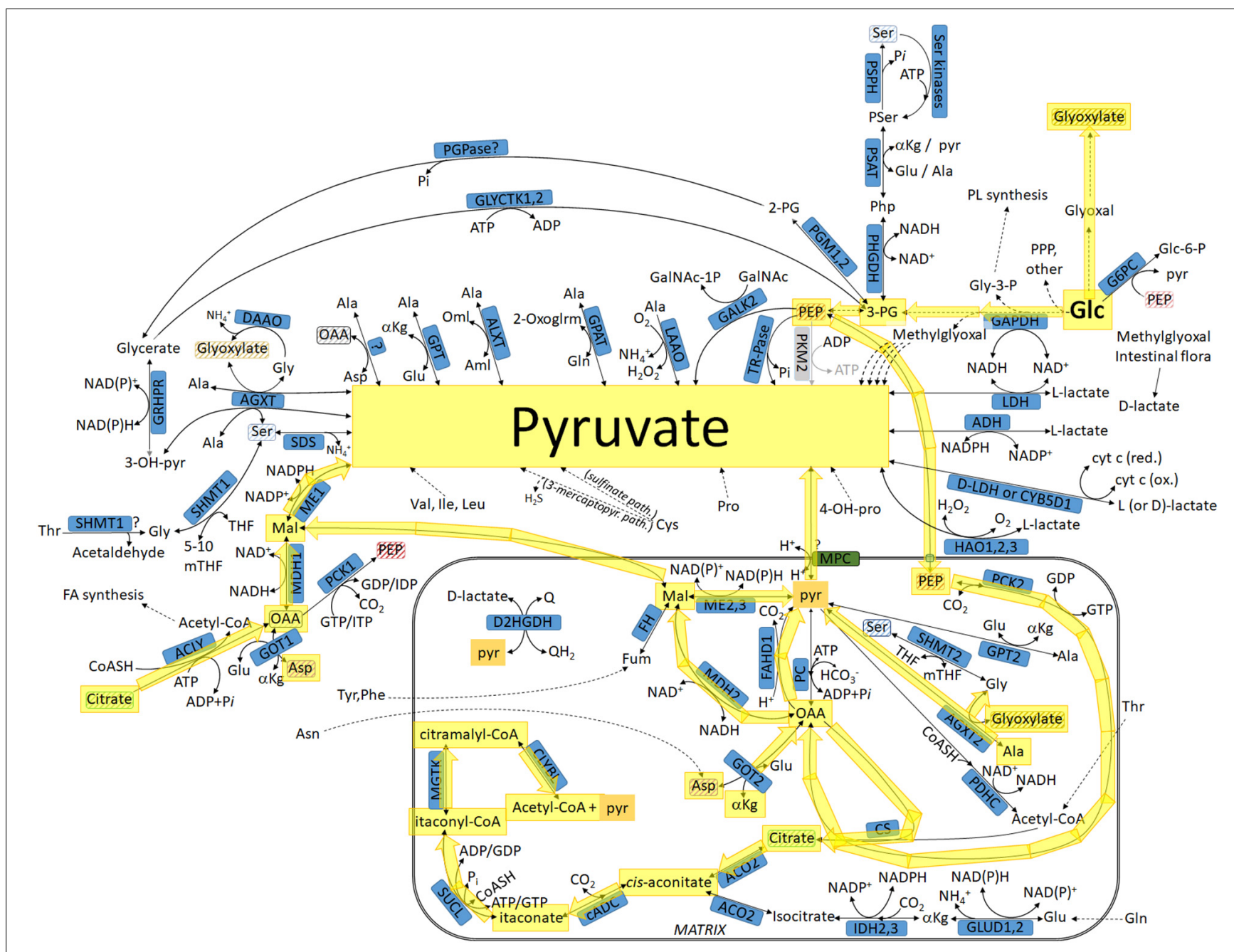

FIGURE 3 | Pathways leading to pyruvate commencing from glucose, highlighted in yellow: intermediates transiting through the mitochondria. For abbreviations, see Table 1.

Nicolay et al., 2015; Capala et al., 2016; Smith et al., 2020).

(13) Glc $\rightarrow \rightarrow \rightarrow$ PEP; PEP enters the mitochondria through the means outlined in pathway 11 ; PEP $\rightarrow$ OAA by PCK2; OAA $\rightarrow$ Mal by $\mathrm{MDH} 2$; Mal $\rightarrow$ pyruvate by ME2,3 (Zelewski and Swierczynski, 1991). Pyruvate may exit the mitochondria through the MPC. ME2 knockdown suppresses tumor growth in lung cancer (Ren et al., 2014), while ME2,3 deletions confer lethality in pancreatic cancer (Dey et al., 2017).

(14) Glc $\rightarrow \rightarrow \rightarrow$ PEP; PEP enters the mitochondria through the means outlined in pathway 11 ; PEP $\rightarrow$ OAA by PCK2; $\mathrm{OAA} \rightarrow \mathrm{Mal}$ by $\mathrm{MDH} 2$; Mal exits the mitochondria; Mal $\rightarrow$ pyruvate by ME1 (Zelewski and Swierczynski, 1991; Loeber et al., 1994). ME1 knockdown inhibits the growth of colon cancer cells (Murai et al., 2017), and its overexpression is associated with larger breast tumor size, higher incidence of lymph node metastasis, and higher incidence of lymph-vascular invasion (Liu C. et al., 2020). In the same line, ME1 is associated with tumor budding-a phenomenon representing epithelial to mesenchymal transition-in oral squamous cell carcinomas (Nakashima et al., 2020).

(15) Glc $\rightarrow \rightarrow \rightarrow$ PEP; PEP enters the mitochondria through the means outlined in pathway 11 ; PEP $\rightarrow$ OAA by PCK2; OAA + acetyl-CoA $\rightarrow$ citrate by $\mathrm{CS}$; citrate exits the mitochondria through the dicarboxylate carrier; citrate $+\mathrm{ATP}+\mathrm{CoASH} \rightarrow$ acetyl-coA $+\mathrm{ADP}+\mathrm{Pi}+\mathrm{OAA}$ by ACLY (Chypre et al., 2012); OAA $\rightarrow$ Mal by MDH1; Mal $\rightarrow$ pyruvate by ME1 (for considerations related to cancer, see pathway no. 14).

(16) Glc $\rightarrow \rightarrow \rightarrow$ PEP; PEP enters the mitochondria through the means outlined in pathway 11 ; PEP $\rightarrow$ OAA by PCK2; $\mathrm{OAA}+\mathrm{Glu} \rightarrow \rightarrow \mathrm{Kg}+$ Asp by GOT2; Asp exits the mitochondria; Asp $+\rightarrow \mathrm{Kg} \rightarrow$ Glu + OAA by GOT1; OAA $\rightarrow$ Mal by MDH1; Mal $\rightarrow$ pyruvate by ME1 (for considerations related to cancer, see pathway no. 14).

(17) Glc $\rightarrow \rightarrow \rightarrow$ PEP; PEP enters the mitochondria through the means outlined in pathway 11 ; PEP $\rightarrow$ OAA by PCK2; $\mathrm{OAA}+$ acetyl-CoA $\rightarrow$ citrate by CS; citrate $\rightarrow$ cis-aconitate, 
intermediate of $\mathrm{ACO} 2$ reaction; cis-aconitate $\rightarrow$ itaconate by cADC; itaconate + CoASH + ATP (or GTP) $\rightarrow$ itaconyl$\mathrm{CoA}+\mathrm{Pi}+\mathrm{ADP}$ (or GDP) by SUCL (Nemeth et al., 2016); itaconyl-CoA $\rightarrow$ citramalyl-CoA by methylglutaconase (MGTK); citramalyl-coA $\rightarrow$ acetyl-CoA + pyruvate by CLYBL (Shen et al., 2017). Pyruvate may exit the mitochondria through the MPC. CLYBL has been reported to be associated with colorectal cancer metastasis (Li and Peng, 2013). Furthermore, CLYBL was reported to be overexpressed in 465 out of 38,258 tumor samples in the COSMIC database ${ }^{8}$.

\section{PATHWAYS LEADING TO PYRUVATE BUT NOT COMMENCING FROM GLUCOSE: INTERMEDIATES NOT TRANSITING THROUGH THE MITOCHONDRIA}

These pathways are shown in Figure 4 (green arrows).

(18) Ser $\rightarrow$ pyruvate, catalyzed by SDS or SDSL (for considerations related to cancer, see pathway no. 6).

(19) Ser $\rightarrow \rightarrow \rightarrow$ PEP; PEP $\rightarrow$ pyruvate; terminal reaction catalyzed by tartrate-resistant acid phosphatase (TR-Pases; for considerations related to cancer, see pathway no. 3).

(20) Ser $\rightarrow \rightarrow \rightarrow$ PEP; PEP + GalNAc $\rightarrow$ GalNAc$1 \mathrm{P}+$ pyruvate. The terminal reaction is catalyzed by $\mathrm{N}$-acetylgalactosamine kinase isoforms 1 or 2 (for considerations related to cancer, see pathway no. 4).

(21) Ala $\rightarrow$ pyruvate, catalyzed by L-amino-acid oxidases (LAAO) (Nakano et al., 1967): Several mammalian LAAOs have been described, of which the enzyme "interleukin-4 induced gene 1" (IL4I1) is the best characterized (Castellano and MolinierFrenkel, 2017); IL4I1 expression was reported to be associated with poor prognosis in human breast cancers (Finak et al., 2008).

(22) Ala + 2-oxoglrm $\rightarrow$ Gln + pyruvate, catalyzed by glutamine-pyruvate transaminase (GPAT) (Cooper and Meister, 1972; Cooper and Kuhara, 2014). GPAT is upregulated in many cancers in a MYC-dependent manner (Dong et al., 2020).

(23) $\mathrm{Ala}+2$-Oml $\rightarrow$ Aml + pyruvate, catalyzed by alanineketomalonate transaminase (ALXT) (Nagayama et al., 1958). I was unable to find relevant literature on ALXT expression or aminomalonate levels and cancer.

(24) Ala $+\alpha \mathrm{Kg} \rightarrow$ Glu + pyruvate, catalyzed by GPT: GPT_-similar to GPAT-is upregulated in many cancers in a MYC-dependent manner (Dong et al., 2020).

(25) Ala + OAA $\rightarrow$ Asp + pyruvate; enzyme unknown (Rowsell, 1956).

(26) Ala + Glyoxylate $\rightarrow$ Gly + pyruvate, catalyzed by alanine-glyoxylate aminotransferase (for considerations related to cancer, see pathway no. 5).

(27) Ala $+3-\mathrm{OH}$-pyr $\rightarrow$ Ser + pyruvate, catalyzed by alanineglyoxylate aminotransferase (for considerations related to cancer, see pathway no. 5).

(28) Thr $\rightarrow$ Gly + acetaldehyde, catalyzed by SHMT1 (Garrow et al., 1993; Pinthong et al., 2014); Gly + 5,10 mTHF

\footnotetext{
${ }^{8} \mathrm{https} / / /$ cancer.sanger.ac.uk/cosmic/gene/analysis?ln=CLYBL
}

$\rightarrow \mathrm{THF}+$ Ser, catalyzed by serine hydroxymethyltransferase 1 ; Ser $\rightarrow$ pyruvate, catalyzed by SDS or SDSL. SHMT1 knockdown induces apoptosis in lung cancer cells (Paone et al., 2014), and SHMT inhibitors block the growth of many human cancer cells (Ducker et al., 2017). Patients with high SHMT2 expression exhibit a shorter overall survival rate compared with patients with low expression (Koseki et al., 2018; for further considerations related to SDS or SDSL and cancer, see pathway no. 6).

(29) Asp $+\alpha \mathrm{Kg} \rightarrow \mathrm{Glu}+$ OAA, catalyzed by GOT1; OAA $\rightarrow$ Mal by MDH1; Mal $\rightarrow$ pyruvate by ME1 (for considerations related to cancer, see pathway no. 14).

(30) 4-OH-proline $\rightarrow \rightarrow \rightarrow$ pyruvate, through glyoxylate formation (see pathway no. 26).

(31) Cys $\rightarrow \rightarrow \rightarrow$ pyruvate through the sulfinate pathway (Stipanuk, 1979, 2020). Notably, in pancreatic cancer cells exhibiting PKM1/2 knockdown, 20\% of intracellular pyruvate originated from cysteine ( $\mathrm{Yu}$ et al., 2019). The contribution of cysteine catabolism to cancer has been extensively reviewed by Serpa (2020).

(32) Cys $\rightarrow$ 3-sulfino-L-alanine catalyzed by aspartate 4-decarboxylase (Liu et al., 2012); 3-sulfino-L-alanine is transaminated to 3-sulfinopyruvate by either aspartate aminotransferase or deaminated to the same product by cysteine sulfinic acid deaminase; 3-sulfinopyruvate is nonenzymatically converted to sulfite and pyruvate (Stipanuk, 2020; for considerations related to cancer, see pathway no. 31).

(33) Cys $\rightarrow \rightarrow \rightarrow \mathrm{H}_{2} \mathrm{~S}+$ pyruvate through the 3mercaptopyruvate pathway (Nagahara and Sawada, 2006). Cys can also transaminate with $\rightarrow$-ketoglutarate to form glutamate and 3-mercaptopyruvate though GOT1, exhibiting cysteine transaminase activity. The catabolism of 3-mercaptopyruvate toward pyruvate is outlined in the reactions below (pathway no. 34; for considerations related to cancer, see pathway no. 31 ).

(34) L-cysteine is isomerized to D-cysteine by cysteine racemase (2-amino-3-mercaptopropionic acid racemase) (Soda and Osumi, 1969); D-Cys is converted to 3-mercaptopyruvate by $\mathrm{D}$-amino acid oxidase and, in turn, to pyruvate and $\mathrm{H}_{2} \mathrm{~S}$ by 3 mercaptopyruvate sulfurtransferase (3MST) (Shibuya et al., 2013) or thiosulfate sulfurtransferase (TST) (Pallini et al., 1991). The possibility of conversion of D-Cys to pyruvate by $\mathrm{D}$-cysteine desulfhydrase (Nagasawa et al., 1985) in mammalian cells is yet to be reported. 3-Mercaptopyruvate can also react with hydrogen cyanide, forming pyruvate and thiocyanate in a reaction catalyzed by $3 \mathrm{MST}$ or TST; obviously, this is only a very minor route of pyruvate production due to cyanide toxicity (Bhandari et al., 2014; for further considerations related to cancer, see pathway no. 31 ).

(35) Ser $\rightarrow$ dehydroalanine (2-aminoacrylate) by serine dehydratase (SDS), serine dehydratase-like protein (SDSL), or serine racemase (SRR): Dehydroalanine can further hydrolyze to $\mathrm{NH}_{3}$ and pyruvate through SDS, SDSL, or SRR (Kashii et al., 2005); sometimes this reaction is referred to as hydrolysis by "2-aminoacrylate aminohydrolase." Dehydroalanine can also spontaneously hydrolyze to $\mathrm{NH}_{3}$ and pyruvate through the intermediate 2-iminopropanoate; the latter later part of this spontaneous hydrolysis can be accelerated by 2-iminopropanoate deaminase (Lambrecht et al., 2012). Dehydroalanine can also 


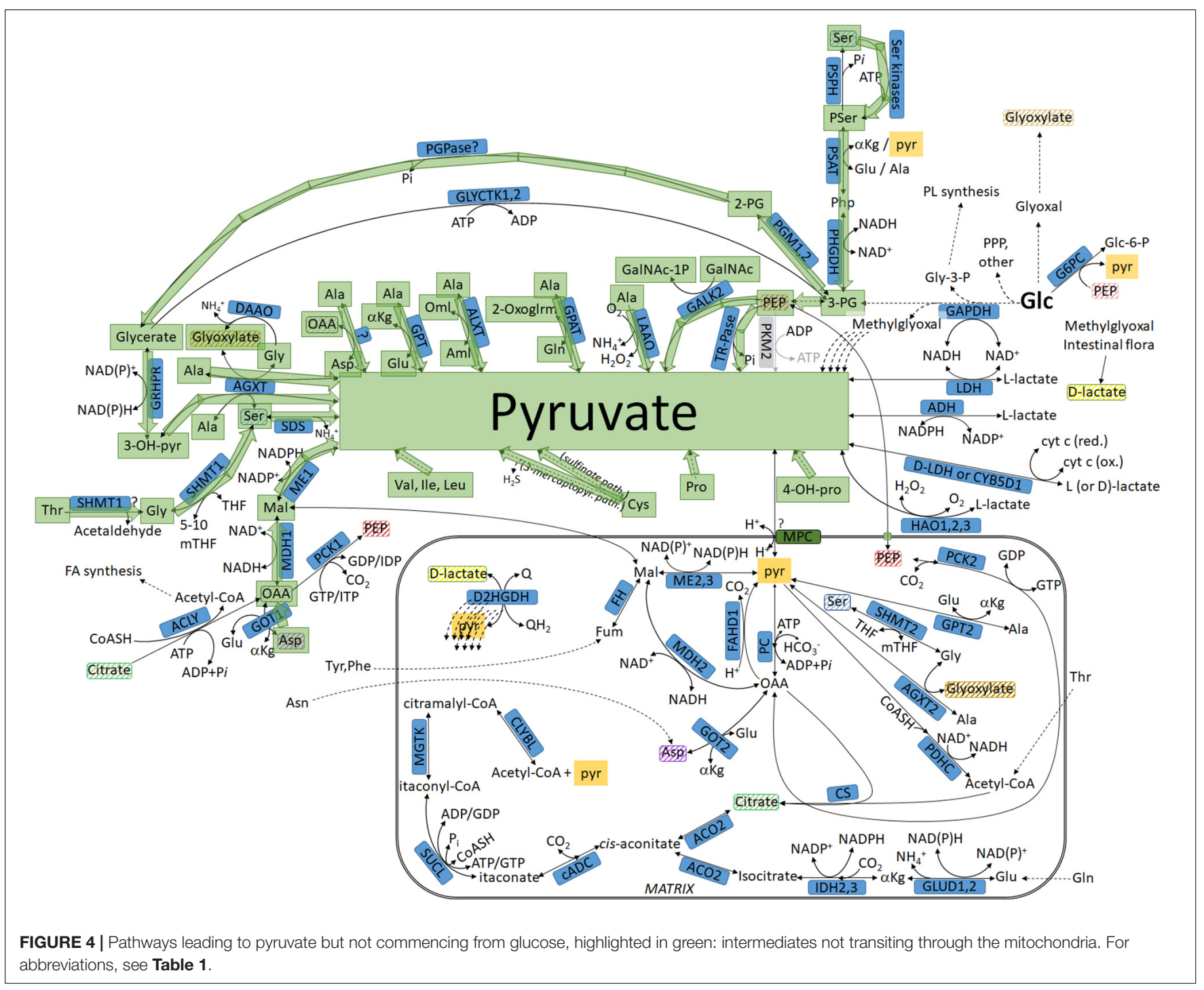

be derived from 2 3,5-diiodo-L-tyrosine or 3,5-diiodo-L-tyrosine by thyroid peroxidase in the process of forming thyroxine and triiodothyronine, respectively (Gavaret et al., 1980). The crucial importance of serine metabolism for the growth and survival of proliferating cells is extensively reviewed in Yang and Vousden (2016) and Newman and Maddocks (2017). (SeMSC, Se-methylselenocysteine,

Se-methyl-L-selenocysteine selenocysteine) can be deaminated to methaneselenol, $\mathrm{NH}_{3}$, and pyruvate by selenocysteine lyase (Esaki et al., 1982). SeMSC can be found in many edible plants, including garlic, onions, and broccoli, as well as in dietary supplements (Yang and Jia, 2014). SeMSC was shown to exhibit anticarcinogenic properties (Ip et al., 1991; Medina et al., 2001) and even potentiate the antitumor activity of anticancer drugs (Cao et al., 2014).

(37) Val $\rightarrow \rightarrow \rightarrow$ 2-methyl-3-oxopropanoate; 2-methyl-3oxopropanoate can get transaminated with alanine by AGXT2 to D-3-amino-isobutanoate + pyruvate (Kakimoto et al., 1969). The overexpression of enzymes participating in valine catabolism is associated with poor prognosis in prostate cancer (Mayers et al., 2016) and tumors of the colon (Shan et al., 2019). The role of valine in cancer has been extensively reviewed in Ananieva and Wilkinson (2018) and Lieu et al. (2020).

(38) Leu $\rightarrow \rightarrow \rightarrow$ 3-methylbutanoyl-CoA; the latter compound is converted to isobutyryl-CoA through branched-chain fatty acid metabolism (many steps); isobutyryl-CoA $\rightarrow \rightarrow \rightarrow$ 2-methyl-3-oxopropanoate; 2-methyl3-oxopropanoate can get transaminated with alanine by AGXT2 to D-3-amino-isobutanoate + pyruvate (Kakimoto et al., 1969). Because leucine catabolism shares many steps with that of valine, for considerations related to cancer, see pathway no. 37 .

(39) Ile $\rightarrow \rightarrow \rightarrow 2$-methylbutanoyl-CoA; the latter compound is converted to isobutyryl-CoA through branched-chain fatty acid metabolism (many steps); isobutyryl-CoA $\rightarrow \rightarrow \rightarrow$ 2-methyl-3-oxopropanoate; 2-methyl-3-oxopropanoate can get transaminated with alanine by AGXT2 to D-3-aminoisobutanoate + pyruvate (Kakimoto et al., 1969). Because 


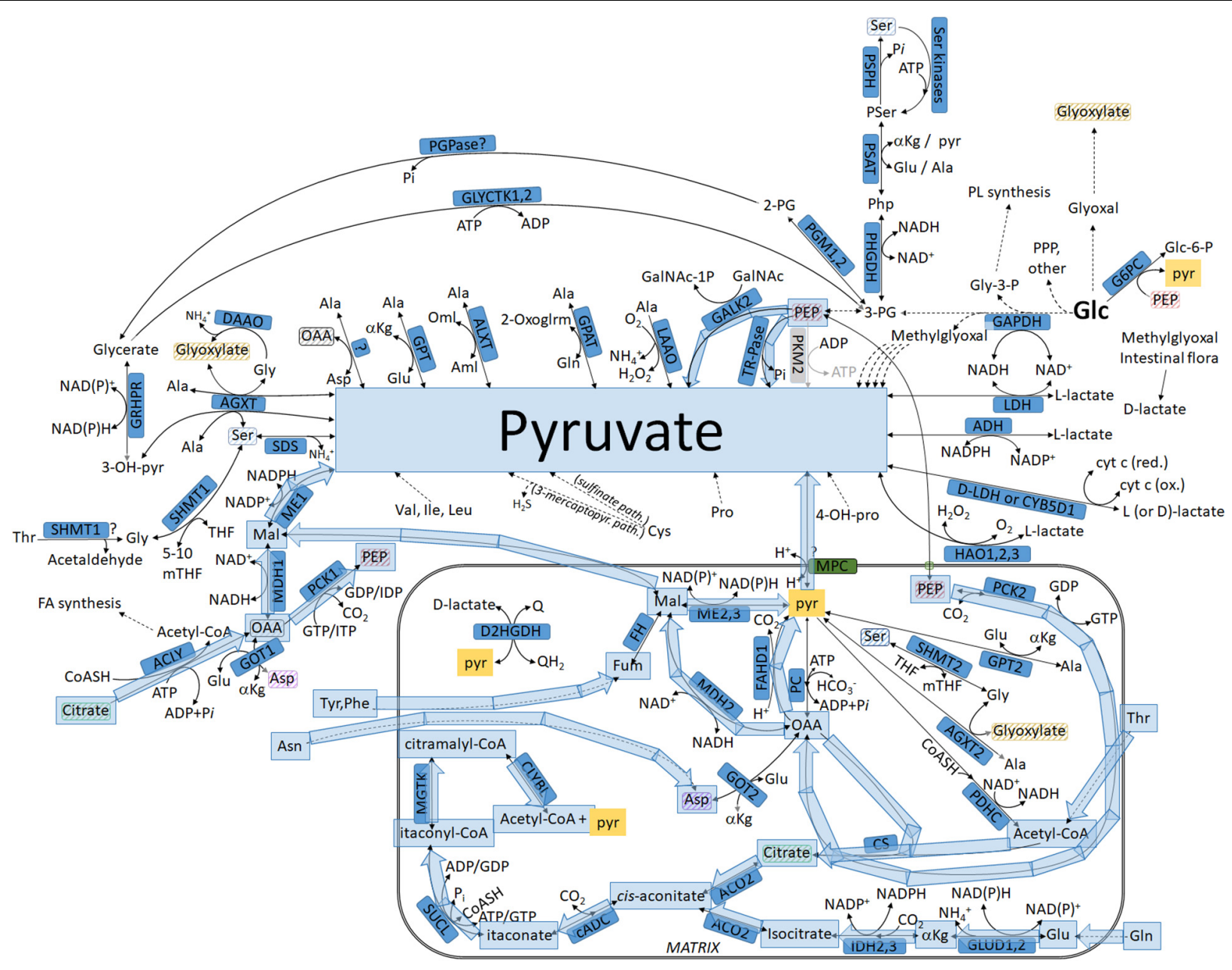

FIGURE 5 | Pathways leading to pyruvate but not commencing from glucose, highlighted in blue: intermediates transiting through the mitochondria. For abbreviations, see Table 1.

isoleucine catabolism shares many steps with that for valine, for considerations related to cancer, see pathway no. 37.

(40) Pro $+\alpha \mathrm{Kg}+\mathrm{O}_{2} \rightarrow \mathrm{CO}_{2}+$ succinate + trans-4hydroxy-L-proline, catalyzed by prolyl 4-hydroxylase subunit alpha (isoforms 1, 2, or 3); trans-4-hydroxy-L-proline is then converted to L-1-pyrroline-3-hydroxy-5-carboxylate, also yielding $\mathrm{NAD}(\mathrm{P}) \mathrm{H}$, by either pyrroline-5-carboxylate reductase (isoforms 1, 2, or 3) or left-right determination factor 1 (LEFTY1), a member of the TGF- $\rightarrow$ family of proteins; L-1-pyrroline-3-hydroxy-5-carboxylate can be converted to L-erythro-4-hydroxyglutamate, also yielding $\mathrm{NAD}(\mathrm{P}) \mathrm{H}$, by aldehyde dehydrogenase 4 family member A1; in turn, L-erythro4-hydroxyglutamate is transaminated with either OAA by GOT2, yielding 4-hydroxy-2-oxoglutarate + aspartate, or $\rightarrow \mathrm{Kg}$ by GOT1 or GOT2, yielding 4-hydroxy-2-oxoglutarate + glutamate; finally, 4-hydroxy-2-oxoglutarate is converted to glyoxylate and pyruvate by 4-hydroxy-2-oxoglutarate glyoxylate-lyase. It is relevant that increased proline catabolism has been recently reported to support metastasis (Elia et al., 2017). Arg, through either interconversion to metabolites as for proline catabolism or through citrulline/ornithine and the fumarate nucleotide cycle will also lead to pyruvate formation; however, this probably requires inter-organ communication and, thus, may not be found within a single cell. The crucial role of proline catabolism in tumor growth and metastatic progression is extensively reviewed in Phang (2019) and D'Aniello et al. (2020).

\section{PATHWAYS LEADING TO PYRUVATE BUT NOT COMMENCING FROM GLUCOSE: INTERMEDIATES TRANSITING THROUGH THE MITOCHONDRIA}

These pathways are shown in Figure 5 (blue arrows).

(41) $\mathrm{Thr} \rightarrow \rightarrow \rightarrow$ acetyl-CoA; acetyl-CoA + OAA $\rightarrow$ citrate, catalyzed by CS; citrate exits the mitochondria through the dicarboxylate carrier; citrate + ATP + CoASH $\rightarrow$ AcetylcoA + ADP + Pi + OAA by ACLY (Chypre et al., 2012); OAA $\rightarrow$ Mal by MDH1; Mal $\rightarrow$ pyruvate by ME1. The 


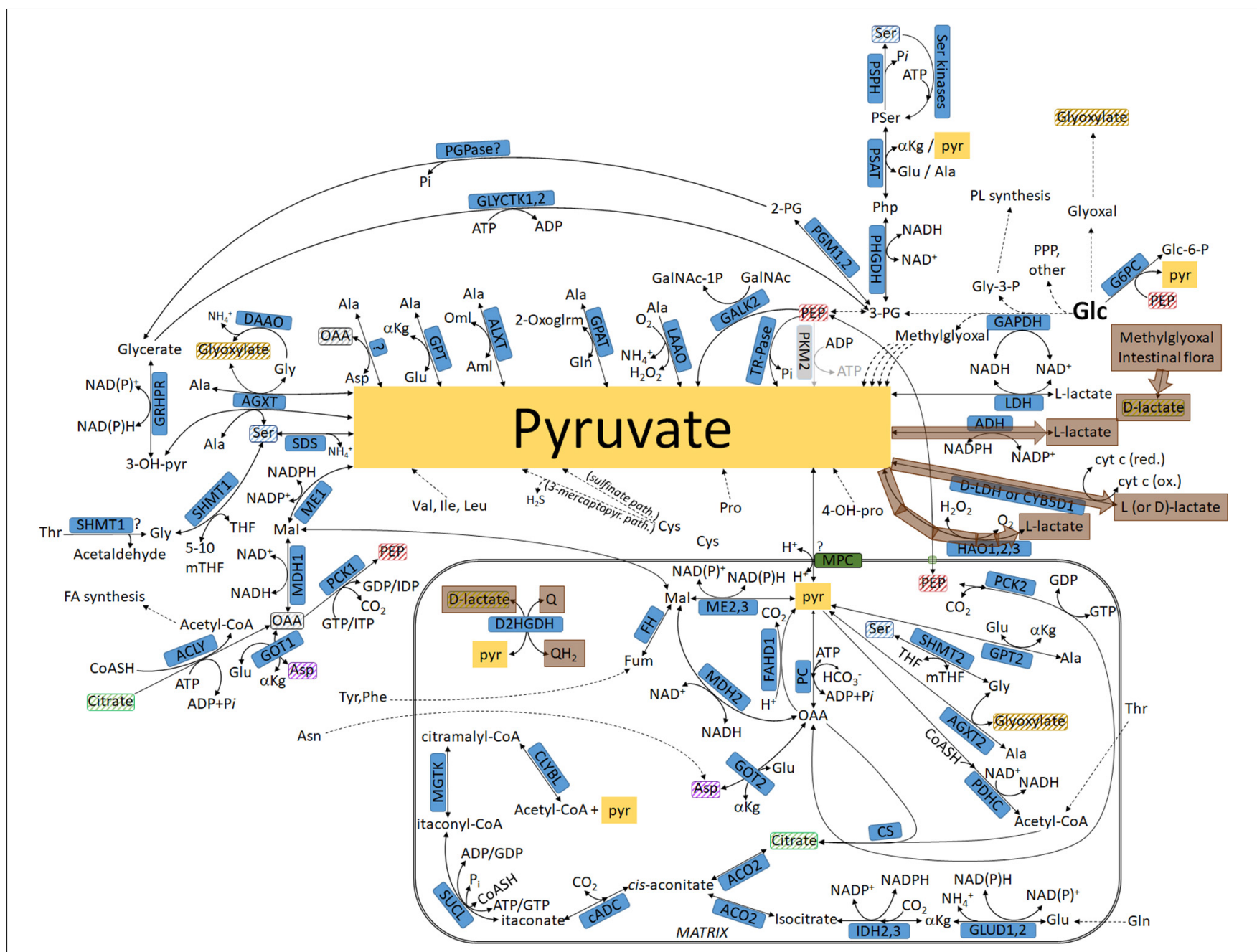

FIGURE 6 | Pathways leading to L-and D-lactate, including those not going through lactate dehydrogenase, highlighted in brown. For abbreviations, see Table 1.

potential role of threonine catabolism in cancer is reviewed in Tsun and Possemato (2015) and Lieu et al. (2020) (for further considerations regarding ME1 and cancer, see pathway no. 14).

(42) $\mathrm{Thr} \rightarrow \rightarrow \rightarrow$ acetyl-CoA; acetyl-CoA + OAA $\rightarrow$ citrate, catalyzed by CS; citrate $\rightarrow$ cis-aconitate, intermediate of $\mathrm{ACO} 2$ reaction; cis-aconitate $\rightarrow$ itaconate by cADC; itaconate $+\mathrm{CoASH}+\mathrm{ATP}$ (or GTP) $\rightarrow$ itaconyl$\mathrm{CoA}+\mathrm{Pi}+\mathrm{ADP}$ (or GDP) by SUCL; itaconyl-CoA $\rightarrow$ citramalyl-CoA by MGTK; citramalyl-coA $\rightarrow$ acetylCoA + pyruvate by CLYBL. Pyruvate may exit the mitochondria through the MPC (regarding threonine and cancer, see pathway no. 41; regarding CLYBL and cancer, see pathway no. 17).

(43) Asn $\rightarrow \rightarrow \rightarrow$ Asp; Asp $+\alpha \mathrm{Kg} \rightarrow$ Glu + OAA by GOT2; OAA by PCK2; OAA $\rightarrow$ pyruvate by reverse operation of PC. However, this is expected to be a path of a very minor flux. Pyruvate may exit the mitochondria through the MPC. The crucial role of asparagine availability in cancer is explored in Panosyan et al. (2014); Krall et al. (2016), and Knott et al. (2018). However, more emphasis on asparagine availability for anabolic, rather than catabolic, purposes is given.
(44) Asn $\rightarrow \rightarrow \rightarrow$ Asp; Asp $+\alpha \mathrm{Kg} \rightarrow$ Glu + OAA by GOT2; OAA $\rightarrow$ pyruvate by acylpyruvase (FAHD1). Pyruvate may exit the mitochondria through the MPC (for considerations related to cancer, see pathways no. 12 and 37).

(45) Asn $\rightarrow \rightarrow \rightarrow$ Asp; Asp $+\alpha \mathrm{Kg} \rightarrow$ Glu + OAA by GOT2; $\mathrm{OAA} \rightarrow \mathrm{Mal}$ by $\mathrm{MDH} 2$; Mal $\rightarrow$ pyruvate by ME2,3. Pyruvate may exit the mitochondria through the MPC (for considerations related to cancer, see pathways no. 13 and 37).

(46) Asn $\rightarrow \rightarrow \rightarrow$ Asp; Asp $+\alpha \mathrm{Kg} \rightarrow \mathrm{Glu}+$ OAA by GOT2; OAA $\rightarrow$ Mal by MDH2; Mal exits the mitochondria; Mal $\rightarrow$ pyruvate by ME1 (for considerations related to cancer, see pathways no. 14 and 37$)$.

(47) Tyr, Phe $\rightarrow \rightarrow \rightarrow$ Fum; Fum $\rightarrow$ Mal by FH; Mal $\rightarrow$ pyruvate by ME2,3 (for considerations related to cancer, see pathway no. 13).

(48) Tyr, Phe $\rightarrow \rightarrow \rightarrow$ Fum; Fum $\rightarrow$ Mal by FH; Mal exits the mitochondria; Mal $\rightarrow$ pyruvate by ME1 (for considerations related to cancer, see pathway no. 14).

(49) Tyr, Phe $\rightarrow \rightarrow \rightarrow$ Fum; Fum $\rightarrow$ Mal by FH; Mal $\rightarrow$ OAA by MDH2; OAA $\rightarrow$ pyruvate by acylpyruvase (FAHD1). Pyruvate 
may exit the mitochondria through the MPC (for considerations related to cancer, see pathway no. 12).

(50) Thr $\rightarrow \rightarrow \rightarrow$ acetyl-CoA; acetyl-CoA + OAA $\rightarrow$ citrate, catalyzed by $\mathrm{CS}$; citrate exits the mitochondria through the dicarboxylate carrier; citrate + ATP + CoASH $\rightarrow$ acetyl$\mathrm{COA}+\mathrm{ADP}+\mathrm{Pi}+\mathrm{OAA}$ by ACLY; OAA $\rightarrow$ PEP by PCK1; $\mathrm{PEP}$ enters the mitochondria; PEP $\rightarrow$ OAA by PCK2; OAA $\rightarrow$ pyruvate by acylpyruvase (FAHD1). Pyruvate may exit the mitochondria through the MPC (for considerations related to cancer, see pathway no. 12).

(51) $\mathrm{Thr} \rightarrow \rightarrow \rightarrow$ acetyl-CoA; acetyl-CoA + OAA $\rightarrow$ citrate, catalyzed by $\mathrm{CS}$; citrate exits the mitochondria through the dicarboxylate carrier; citrate + ATP + CoASH $\rightarrow$ acetyl$\mathrm{COA}+\mathrm{ADP}+\mathrm{Pi}+\mathrm{OAA}$ by ACLY; OAA $\rightarrow$ PEP by PCK1; $\mathrm{PEP}$ enters mitochondria; $\mathrm{PEP} \rightarrow \mathrm{OAA}$ by $\mathrm{PCK} 2$; OAA $\rightarrow \mathrm{Mal}$ by $\mathrm{MDH} 2$; Mal $\rightarrow$ pyruvate by ME2,3. Pyruvate may exit the mitochondria through the MPC (for considerations related to cancer, see pathway no. 13).

(52) $\mathrm{Thr} \rightarrow \rightarrow \rightarrow$ acetyl-CoA; acetyl-CoA + OAA $\rightarrow$ citrate, catalyzed by $\mathrm{CS}$; citrate exits the mitochondria through the dicarboxylate carrier; citrate + ATP + CoASH $\rightarrow$ acetyl$\mathrm{CoA}+\mathrm{ADP}+\mathrm{Pi}+\mathrm{OAA}$ by ACLY; OAA $\rightarrow$ PEP by PCK1; PEP enters the mitochondria; $\mathrm{PEP} \rightarrow$ OAA by $\mathrm{PCK} 2$; OAA $\rightarrow \mathrm{Mal}$ by $\mathrm{MDH} 2$; Mal exits the mitochondria; Mal $\rightarrow$ pyruvate by ME1 (for considerations related to cancer, see pathway no. 14).

(53) $\mathrm{Thr} \rightarrow \rightarrow \rightarrow$ acetyl-CoA; acetyl-CoA + OAA $\rightarrow$ citrate, catalyzed by $\mathrm{CS}$; citrate exits the mitochondria through the dicarboxylate carrier; citrate + ATP + CoASH $\rightarrow$ Acetyl$\mathrm{COA}+\mathrm{ADP}+\mathrm{Pi}+\mathrm{OAA}$ by ACLY; OAA $\rightarrow$ PEP by PCK1; $\mathrm{PEP}+\mathrm{GalNAc} \rightarrow$ GalNAc-1P + pyruvate. Terminal reaction catalyzed by $\mathrm{N}$-acetylgalactosamine kinase isoforms 1 or 2 (for considerations related to cancer, see pathway no. 4).

(54) $\mathrm{Thr} \rightarrow \rightarrow \rightarrow$ acetyl-CoA; acetyl-CoA + OAA $\rightarrow$ citrate, catalyzed by $\mathrm{CS}$; citrate exits the mitochondria through the dicarboxylate carrier; citrate + ATP + CoASH $\rightarrow$ acetyl$\mathrm{COA}+\mathrm{ADP}+\mathrm{Pi}+\mathrm{OAA}$ by ACLY; OAA $\rightarrow$ PEP by PCK1; $\mathrm{PEP} \rightarrow$ pyruvate; the terminal reaction is catalyzed by tartrateresistant acid phosphatases (for considerations related to cancer, see pathway no. 3 ).

\section{INCOMPLETELY CHARACTERIZED REACTIONS FORMING PYRUVATE}

In the literature, some reactions have been described to produce pyruvate but are incompletely characterized. These are collectively listed below:

(55) O-carbamoyl-L-serine $+\mathrm{H}_{2} \mathrm{O} \rightarrow$ pyruvate $+2 \mathrm{NH}_{3}$, catalyzed by carbamoyl-serine ammonia lyase (Copper and Meister, 1973). O-Carbamoyl-L-serine is a weak inhibitor of a phosphate-dependent glutaminase (Shapiro et al., 1979); mindful of the crucial importance of glutamine catabolism through glutaminases in many cancer types, this route of pyruvate provision is probably minor.

(56) L-Cysteine-S-conjugate $+\mathrm{H}_{2} \mathrm{O} \rightarrow \mathrm{a}$ thiol $+\mathrm{NH}_{3}+$ pyruvate, catalyzed by cysteine $\mathrm{S}$-conjugate $\rightarrow$-lyases (Cooper and Pinto, 2006). The possibility of cysteine S-conjugate $\beta$-lyases metabolizing anticancer agents is reviewed in Cooper et al. (2011).

(57) cystathionine $+\mathrm{H}_{2} \mathrm{O} \rightarrow$ L-homocysteine + pyruvate + $\mathrm{NH}_{3}$ or cysteine $+\mathrm{H}_{2} \mathrm{O} \rightarrow$ sulfide $+\mathrm{NH}_{3}+$ pyruvate or cystine $\rightarrow$ thiocysteine + pyruvate $+\mathrm{NH}_{3}$, all catalyzed by cystathionine gamma-lyase (Stipanuk et al., 2006; Chiku et al., 2009). Cystathionine gamma-lyase was reported to be upregulated in bone-metastatic PC3 cells, and its knockdown suppressed tumor growth and metastasis (Wang et al., 2019). In the same line, this enzyme was shown to be upregulated and played a crucial role in the proliferation and migration of breast cancer cells (You et al., 2017).

(58) $\mathrm{L}$-Serine $\mathrm{O}$-sulfate $+\mathrm{H}_{2} \mathrm{O} \rightarrow$ pyruvate $+\mathrm{NH}_{3}+$ sulfate catalyzed by serine-sulfate ammonia-lyase (Tudball and Thomas, 1972). I was unable to find relevant literature on serine-sulfate ammonia-lyase expression or L-serine O-sulfate levels and cancer.

(59) N-Acetylneuraminate $\rightarrow \mathrm{N}$-acetyl-D-mannosamine + pyruvate catalyzed by $\mathrm{N}$-acetylneuraminate lyase (Brunetti et al., 1962); relevant to this, treatment of HL-60 cells by phorbol esters leads to a marked increase in the activity of this enzyme (Warren, 1986).

(60) D-Alanine $+\mathrm{H}_{2} \mathrm{O}+\mathrm{O}_{2} \rightarrow$ pyruvate $+\mathrm{NH}_{3}+\mathrm{H}_{2} \mathrm{O}_{2}$ catalyzed by DAAO (Nagata et al., 1992; Abe et al., 2005; Fuchs et al., 2005; Smith et al., 2009). The interaction of D-alanine (and other D-amino acids) with tumors is reviewed in Bastings et al. (2019).

(61) L-Alanine $\rightarrow$ pyruvate $+\mathrm{NH}_{3}$ catalyzed by glutamate dehydrogenase; this reaction exhibits a weak activity (Silverstein, 1974). The role of glutamate dehydrogenase in cancer cells has been extensively reviewed in Moreno-Sanchez et al. (2020).

(62) 2-Oxosuccinamic acid + Ala $\rightarrow$ Asn + pyruvate, catalyzed by asparagine aminotransferase (Cooper, 1977; Maul and Schuster, 1986). The origin of 2-oxosuccinamic acid is not known (Cooper et al., 1987). I was unable to find relevant literature on 2-oxosuccinamic acid levels and cancer.

(63) Pyruvate oxime + acetone $\rightarrow$ pyruvate + acetone oxime, catalyzed by oximinotransferase (Omura et al., 1956). Due to acetone volatility, this is probably a very minor pathway for pyruvate production.

(64) Methylmalonyl-CoA + pyruvate $\rightarrow$ propionyl$\mathrm{CoA}+$ oxaloacetate catalyzed by methylmalonyl-CoA carboxytransferase (Swick and Wood, 1960). This reaction is reversible and thus may yield pyruvate. I was unable to find relevant literature on methylmalonyl-CoA carboxytransferase and cancer.

(65) L-Alanine + 3-oxopropanoate $\rightarrow$ pyruvate $+\rightarrow$ alanine, catalyzed by either $\rightarrow$-alanine-pyruvate transaminase (Ito et al., 2001) or alanine-glyoxylate aminotransferase isoform 2 (Lee et al., 1995) (for considerations related to cancer, see pathway no. 5).

(66) Phenylpyruvate + L-alanine $\rightarrow$ L-phenylalanine + pyruvate catalyzed by phenylalanine (histidine) transaminase (Minatogawa et al., 1977). Phenylpyruvate has been reported to inhibit pyruvate kinase activity in human brain (Weber, 1969), thus enhancing PK-bypassing pathways. Phenylpyruvate 
levels were also found to be increased in ovarian cancers (Fong et al., 2011).

(67) 2-Oxoisohexanoate + L-alanine $\rightarrow$ L-leucine + pyruvate, catalyzed by the mitochondrial branched-chain L-amino acid aminotransferase (Schadewaldt et al., 1995). The role of branched-chain L-amino acid aminotransferase in cancer has been reviewed in Ananieva and Wilkinson (2018).

(68) PCK1, ME1, and ME2,3 may also convert OAA to $\mathrm{CO}_{2}$ and pyruvate (Sauer, 1973; Carlson et al., 1978; Bukato et al., 1995; Lee et al., 1995) (for considerations related to cancer, see pathway nos. 13 and 14).

(69) Salsolinol can be converted to salsolinol-1-carboxylate by salsolinol synthetase which can then be catabolized to dopamine and pyruvate (by an unknown enzyme); salsolinol is an endogenous catechol isoquinoline detected in humans derived from dopamine metabolism (Sandler et al., 1973; Collins et al., 1979). Salsolinol has been implicated in the initiation and promotion of alcohol-related breast carcinogenesis (Murata et al., 2016).

\section{PATHWAYS LEADING TO L-LACTATE AND D-LACTATE INCLUDING THOSE NOT GOING THROUGH LACTATE DEHYDROGENASE}

These pathways are shown in Figure 6 (brown arrows).

Lactate-unlike pyruvate-exhibits chirality; thus, it exists in L- or D- configuration. In humans, a putative D-lactate dehydrogenase is known to exist (Flick and Konieczny, 2002; Ewaschuk et al., 2005; Chen et al., 2015). In metabolomics experiments, it is uncommon to distinguish between L- and D-lactate even although it is possible by using special columns. In this section, D- and L-lactateforming pathways are outlined, including those not going through LDH:

(70) D-lactate formation by methylglyoxal and intestinal flora (Chen et al., 2015) (for considerations related to cancer, see pathway no. 2).

(71) Pyruvate $+\mathrm{QH}_{2} \rightarrow$ D-lactate $+\mathrm{Q}$, catalyzed by D2HGDH in the mitochondrial matrix (Cammack, 1969, 1970). Mutations in $\mathrm{D} 2 \mathrm{HGDH}$ have been reported to be involved in multiple types of cancers but render the enzyme hypoactive or inert (Ye et al., 2018); thus, it is unlikely for this route to be important regarding pyruvate production.

(72) D- (or L-) Lactate +2 ferricytochrome $\rightarrow 2$ ferrocytochrome $\mathrm{C}+2 \mathrm{H}^{+}+$pyruvate, catalyzed by $\mathrm{D}$-lactate dehydrogenase; this reaction is mentioned in several databases, but no reference is given.

(73) D- (or L-) Lactate +2 ferricytochrome $\rightarrow 2$ ferrocytochrome $\mathrm{C}+2 \mathrm{H}^{+}+$pyruvate, catalyzed by cytochrome B5 domain-containing protein 1; this reaction is mentioned in several databases, but no reference is given.

(74) Pyruvate $+\mathrm{NADPH} \rightarrow \mathrm{NADP}^{+}+$L-lactate, catalyzed by ADH (Bosron and Prairie, 1972). The many roles of $\mathrm{ADH}$ in malignant neoplasms have been extensively reviewed in Orywal and Szmitkowski (2017).
(75) Pyruvate $+\mathrm{H}_{2} \mathrm{O}_{2} \rightarrow$ L-lactate $+\mathrm{O}_{2}$, catalyzed by hydroxyacid oxidases (HAO1,2,3) (Fry and Richardson, 1979; Vignaud et al., 2007). However, in Jones et al. (2000), no HAO activity was reported. In primary pancreatic tumors, $\mathrm{HAO} 3$ is strongly downregulated (Thakur et al., 2008). HAO2 was reported to inhibit the malignancy of clear cell renal cell carcinoma cells. Overall, it is unlikely for this to be a substantial pathway in yielding pyruvate in cancer.

(76) Protein deglycase (E.C. 3.5.1.124) may form D-lactate from proteins (Richarme et al., 2015; Richarme and Dairou, 2017). Relevant to this, the deglycase DJ-1/Park7 is important for cancer cell survival (Vasseur et al., 2009).

(77) Methylglyoxal spontaneously forms a hemithioacetal adduct with GSH; subsequently, glyoxalase I (lactoylglutathione lyase; EC 4.4.1.5) produces S-D-lactoylglutathione from this adduct (Thornalley, 1990), and glyoxalase II (hydroxyacylglutathione hydrolase; EC 3.1.2.6), in turn, hydrolyzes S-D-lactoylglutathione to D-lactate $+\mathrm{GSH}$ (Cordell et al., 2004) (for considerations related to cancer, see pathway no. 2).

Finally, it is worth mentioning that $\mathrm{LDH}$ may process substrates other than pyruvate and lactate, interconverting glyoxylate $+\mathrm{NAD}^{+}$to oxalate $+\mathrm{NADH}$ or $\alpha$-ketobutyrate to $\rightarrow$-hydroxybutyrate or L-glycerate to hydroxypyruvate (Dawkins and Dickens, 1965; Kim and Whitesides, 1988).

\section{PATHWAYS LEADING TO PYRUVATE COMMENCING FROM GLUTAMINE (GLUTAMINOLYSIS)}

It is a well-known fact that most cancer cells grow much better when feeding media contain glutamine; this spurred from the pioneering studies of Eagle et al. (1956), showing the dependence of cancer cells growing in monolayer cultures on glutamine. The many critical roles of glutamine in tumor metabolism is reviewed in Altman et al. (2016). From the energetic point of view it were Reitzer et al. (1979) who first showed that glutamine, not sugars, is the main energy source in cultured HeLa cells and that carbon atoms from glutamine incorporate into lactate, but not more than 13\%. Zielke et al. (1980), likewise reported that human diploid fibroblasts metabolize up to $13 \%$ of media glutamine to lactate. In the same line of thought, Scott et al. (2011), showed that, in human melanoma cell lines, glutamine did not significantly label lactate, in agreement with the data of Ta and Seyfried (2015) reporting that, in a murine glioblastoma cell line, minimal amounts of lactate derived from glutamine were detected. Le et al. (2012), as well as Son et al. (2013) likewise showed that ${ }^{13} \mathrm{C}$-labeled atoms in glutamine appear in lactate also to a minimal extent. However, in a study published by DeBerardinis et al. (2007), 60\% of the glutamine metabolized by SF188 cells was claimed to be converted to lactate, although they seemed to combine this percentage with that of alanine production. The pathway of converting glutamine to pyruvate (and lactate), referred to by McKeehan (1982) as "glutaminolysis," has been considered a hallmark of tumor metabolism; however, this is a misconception: in normal tissues, 


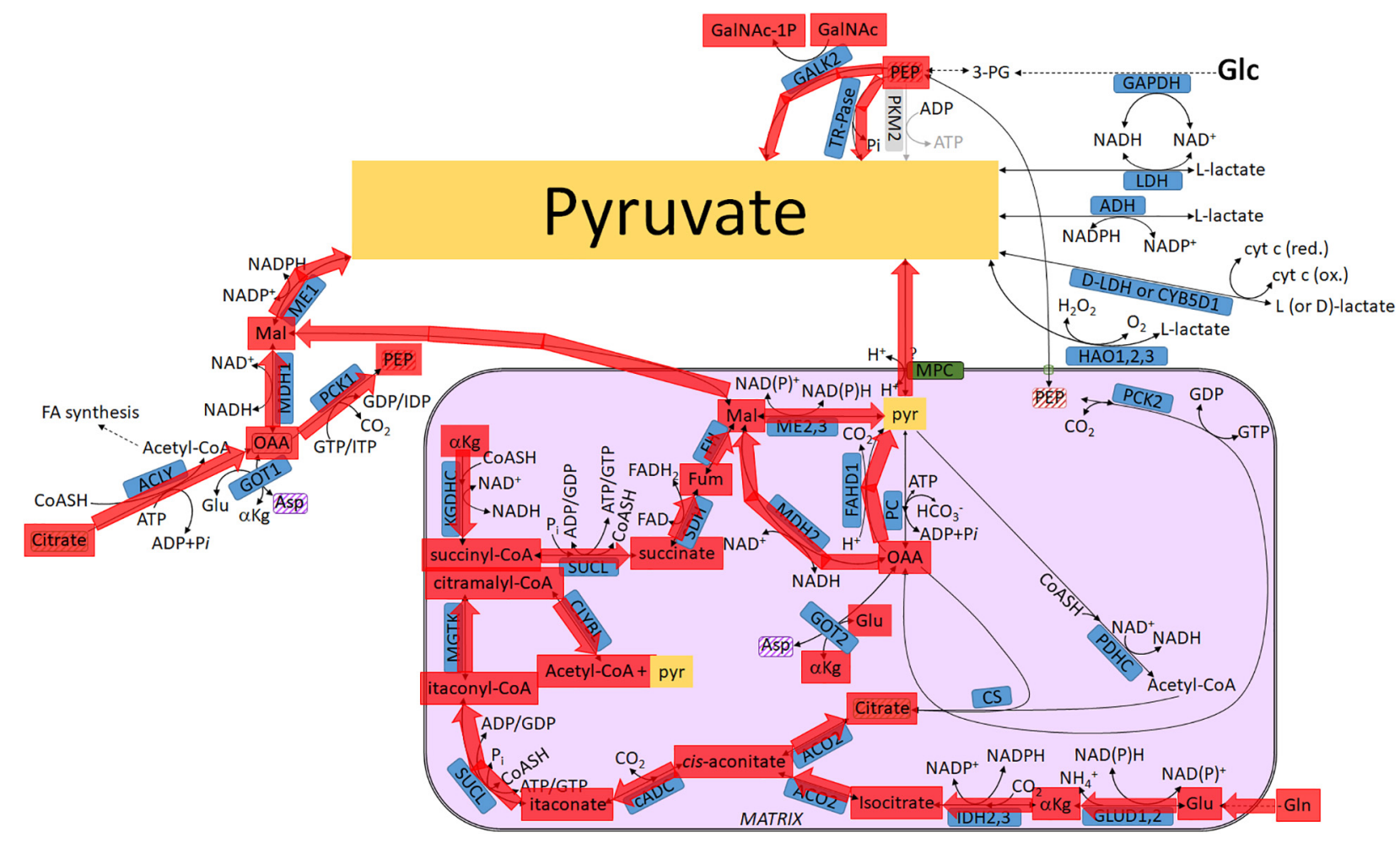

FIGURE 7 | Pathways leading to pyruvate commencing from glutamine (glutaminolysis), highlighted in red. For abbreviations, see Table 1.

$\sim 18 \%$ of glutamine carbons appear in lactate (Windmueller and Spaeth, 1974), as opposed to $\sim 10-13 \%$ (or less) in tumor cells (see the references above). Thus, if anything, cancer cells exhibit a decrease in glutamine-to-lactate conversion exactly as anticipated, mindful that glutamine provides both energy and building blocks for several biosynthetic processes of cancer. Although glutaminolysis was originally attributed to the pathway Gln $\rightarrow$ Glu $\rightarrow$ aKg $\rightarrow$ succinyl-CoA $\rightarrow$ succinate $\rightarrow$ fumarate $\rightarrow$ malate (exiting the mitochondria) $\rightarrow$ pyruvate (through malic enzyme), several other routes may also contribute (outlined below; see Figure 7).

(78) (For the sake of completion, the glutaminolysis pathway proposed by McKeehan (1982) is repeated in the present entry) Gln $\rightarrow$ Glu $\rightarrow$ aKg $\rightarrow$ succinyl-CoA $\rightarrow$ succinate $\rightarrow$ fumarate $\rightarrow$ malate; malate exits the mitochondria $\rightarrow$ pyruvate; this last step is catalyzed by cytosolic malic enzyme (ME1).

(79) $\mathrm{Gln} \rightarrow$ Glu $\rightarrow$ aKg $\rightarrow$ isocitrate $\rightarrow$ cis-aconitate $\rightarrow$ itaconate by cADC; itaconate + CoASH + ATP $($ or GTP) $\rightarrow$ itaconyl-CoA $+\mathrm{Pi}+\mathrm{ADP}$ (or GDP) by SUCL (Nemeth et al., 2016); itaconyl-CoA $\rightarrow$ citramalyl-CoA by methylglutaconase (MGTK); citramalyl$\mathrm{coA} \rightarrow$ acetyl-CoA + pyruvate by CLYBL (Shen et al., 2017). Pyruvate may exit the mitochondria through the MPC.

(80) $\mathrm{Gln} \rightarrow$ Glu $\rightarrow$ aKg $\rightarrow$ isocitrate $\rightarrow$ cis-aconitate $\rightarrow$ citrate, exiting the mitochondria $\rightarrow$ citrate $+\mathrm{ATP}+\mathrm{CoASH} \rightarrow$
acetyl-coA + ADP + Pi + OAA by ACLY (Chypre et al., 2012); $\mathrm{OAA} \rightarrow \mathrm{Mal}$ by MDH1; Mal $\rightarrow$ pyruvate by ME1.

(81) Gln $\rightarrow$ Glu $\rightarrow$ aKg $\rightarrow$ isocitrate $\rightarrow$ cis-aconitate $\rightarrow$ citrate, exiting the mitochondria $\rightarrow$ citrate $+\mathrm{ATP}+\mathrm{CoASH} \rightarrow$ acetyl-coA $+\mathrm{ADP}+\mathrm{Pi}+\mathrm{OAA}$ by ACLY; OAA $\rightarrow$ PEP by PCK1; $\mathrm{PEP}+\mathrm{GalNAc} \rightarrow$ GalNAc-1P + pyruvate. The terminal reaction is catalyzed by $\mathrm{N}$-acetylgalactosamine kinase isoforms 1 or 2 .

(82) Gln $\rightarrow$ Glu $\rightarrow$ aKg $\rightarrow$ isocitrate $\rightarrow$ cis-aconitate $\rightarrow$ citrate, exiting the mitochondria $\rightarrow$ citrate + ATP + CoASH $\rightarrow$ acetyl-coA + ADP $+\mathrm{Pi}+\mathrm{OAA}$ by ACLY; OAA $\rightarrow$ PEP by $\mathrm{PCK} 1$; PEP $\rightarrow$ pyruvate; the terminal reaction is catalyzed by tartrate-resistant acid phosphatases.

(83) $\mathrm{Gln} \rightarrow \mathrm{Glu} \rightarrow$ aKg $\rightarrow$ succinyl-CoA $\rightarrow$ succinate $\rightarrow$ fumarate $\rightarrow$ malate $\rightarrow$ pyruvate by ME2,3; pyruvate may exit the mitochondria through the MPC.

(84) Gln $\rightarrow$ Glu $\rightarrow$ aKg; aKg transaminates with Asp forming Glu and OAA, by GOT2; OAA $\rightarrow$ pyruvate by FAHD1 (Pircher et al., 2011, 2015); pyruvate may exit the mitochondria through the MPC.

(85) Gln $\rightarrow$ Glu $\rightarrow$ aKg; aKg transaminates with Asp forming Glu and OAA, by GOT2; OAA $\rightarrow$ Mal by MDH2; Mal exits the mitochondria; Mal $\rightarrow$ pyruvate by ME1 (Zelewski and Swierczynski, 1991; Loeber et al., 1994).

(86) Gln $\rightarrow$ Glu $\rightarrow$ aKg; aKg transaminates with Asp forming Glu and OAA, by GOT2; OAA $\rightarrow$ Mal by MDH2; malate $\rightarrow$ pyruvate by ME2,3; pyruvate may exit the mitochondria through the MPC. 


\section{ENERGETICS OF GLYCOLYSIS WITH KINETICALLY INACTIVE PK}

Glycolysis yields a net of two ATP molecules per glucose molecule; however, in view of an inactive PK while pyruvate is made through PK-bypass pathways, net ATP production from glycolysis is expected to be zero. Although the importance of high-energy phosphate generation has been downplayed in cancer tissues (Vander Heiden et al., 2009), it cannot be ignored that-according to the BRENDA database-among the 336 enzymatic reactions requiring ATP in a cell (without even considering quantitatively important, non-enzymatic mechanisms such as $\mathrm{Na}^{+} / \mathrm{K}^{+}$ATPase), 125 of them occur in the cytosol. Clearly, while it is imperative to prevent phosphofructokinase and hexokinase from ATP-dependent feedback inhibition and allow a high flux of glycolysis for the sake of generating intermediates shuttled toward other pathways, ATP is still needed for many other reactions. Crunching the numbers regarding cytosolic energetics is a daunting task, but what is definite is that a cell with nearly zero ATP production from glycolysis may not harbor ATP-consuming mitochondria, for whatever reason (hypoxia, mtDNA mutations, etc.). This can be solved by maintaining the adenine nucleotide translocase in "forward" mode, i.e., providing ATP to the cytosol which is made by SUCL supported by glutaminolysis (Chinopoulos et al., 2010). Production of pyruvate and, therefore lactate is still maintained by the PK-bypassing pathways so as to thwart a reductive stress as pyruvate-to-lactate by LDH maintains a low $\mathrm{NADH} / \mathrm{NAD}^{+}$ratio. Finally, it is important to emphasize that this lack of ATP generation by glycolysis due to PK inhibition does not only occur in neoplastic tissues, but it seems to be a more general pathophysiological mechanism also present in tissue ischemia: it was recently reported that during acute kidney injury, PK was inhibited by oxidative/nitrosative stress for the purpose of diverting glycolytic intermediates toward the pentose phosphate pathway which, in turn, yielded reducing equivalents and mounted a better response during the reperfusion phase where ROS are formed, thus increasing the chances for organ survival (Zhou et al., 2019).

\section{REFERENCES}

Abbadi, S., Rodarte, J. J., Abutaleb, A., Lavell, E., Smith, C. L., Ruff, W., et al. (2014). Glucose-6-phosphatase is a key metabolic regulator of glioblastoma invasion. Mol. Cancer Res. 12, 1547-1559. doi: 10.1158/1541-7786.mcr-140106-t

Abe, H., Yoshikawa, N., Sarower, M. G., and Okada, S. (2005). Physiological function and metabolism of free D-alanine in aquatic animals. Biol. Pharm. Bull. 28, 1571-1577. doi: 10.1248/bpb.28.1571

Alquraishi, M., Puckett, D. L., Alani, D. S., Humidat, A. S., Frankel, V. D., Donohoe, D. R., et al. (2019). Pyruvate kinase M2: a simple molecule with complex functions. Free Radic. Biol. Med. 143, 176-192. doi: 10.1016/j.freeradbiomed. 2019.08.007

Altenberg, B., and Greulich, K. O. (2004). Genes of glycolysis are ubiquitously overexpressed in 24 cancer classes. Genomics 84, 1014-1020. doi: 10.1016/j. ygeno.2004.08.010

Altman, B. J., Stine, Z. E., and Dang, C. V. (2016). From Krebs to clinic: glutamine metabolism to cancer therapy. Nat. Rev. Cancer 16, 619-634. doi: 10.1038/nrc. 2016.71

\section{CONCLUSION}

The above considerations aim to (i) highlight that L-lactate can still be produced from pyruvate using carbon atoms originating from glucose or other substrates in cells with kinetically impaired pyruvate kinase and (ii) show that the mitochondria may contribute to cancer metabolism irrespective of oxidative phosphorylation by providing means of contributing to pyruvate production. Having said that, it is important to emphasize that none of the aforementioned reactions take into account the potential regulatory effects of metabolites on other reactions such as those occurring on PK by amino acids (Chaneton et al., 2012; Yuan et al., 2018). In addition, each enzyme probably exhibits different kinetic and thermodynamic constraints which control the overall flux, which also means that many of these pathways may not operate simultaneously. Such exponentially increasing complexity of a system precludes the possibility of predictions and modeling, though I would be happy to be proven wrong.

\section{AUTHOR CONTRIBUTIONS}

CC wrote and edited the manuscript.

\section{FUNDING}

This work was supported by grants from NKFIH (FIKP-6182264888-EATV, VEKOP 2.3.3-15-2016-00012, 2017-2.3.4-TET-RU2017-00003, KH129567, and K135027) to CC.

\section{ACKNOWLEDGMENTS}

I am indebted to Dr. Dora Ravasz, Dr. David Bui, Jeonghyoun Lee, and Seung Won Jeong for assistance with database mining and to Prof. Thomas N. Seyfried for helpful discussions.

Ananieva, E. A., and Wilkinson, A. C. (2018). Branched-chain amino acid metabolism in cancer. Curr. Opin. Clin. Nutr. Metab. Care 21, 64-70. doi: 10.1097/mco.0000000000000430

Anastasiou, D., Poulogiannis, G., Asara, J. M., Boxer, M. B., Jiang, J. K., Shen, M., et al. (2011). Inhibition of pyruvate kinase M2 by reactive oxygen species contributes to cellular antioxidant responses. Science 334, 1278-1283. doi: 10.1126/science.1211485

Anastasiou, D., Yu, Y., Israelsen, W. J., Jiang, J. K., Boxer, M. B., Hong, B. S., et al. (2012). Pyruvate kinase M2 activators promote tetramer formation and suppress tumorigenesis. Nat. Chem. Biol. 8, 839-847.

Antognelli, C., Moretti, S., Frosini, R., Puxeddu, E., Sidoni, A., and Talesa, V. N. (2019). Methylglyoxal Acts as a Tumor-Promoting Factor in Anaplastic Thyroid Cancer. Cells 8, 547. doi: 10.3390/cells8060547

Baker, P. R., Cramer, S. D., Kennedy, M., Assimos, D. G., and Holmes, R. P. (2004). Glycolate and glyoxylate metabolism in HepG2 cells. Am. J. Physiol. Cell Physiol. 287, C1359-C1365.

Baranowski, T., Wolna, E., and Morawiecki, A. (1968). Purification and properties of crystalline 2-phospho-D-glycerate hydro-lyase from human muscle. Eur. J. Biochem. 5, 119-123. doi: 10.1111/j.1432-1033.1968.tb00345.x 
Bartesaghi, S., Graziano, V., Galavotti, S., Henriquez, N. V., Betts, J., Saxena, J., et al. (2015). Inhibition of oxidative metabolism leads to p53 genetic inactivation and transformation in neural stem cells. Proc. Natl. Acad. Sci. U.S.A. 112, 1059-1064. doi: 10.1073/pnas.1413165112

Bastings, J., van Eijk, H. M., Olde Damink, S. W., and Rensen, S. S. (2019). damino acids in health and disease: a focus on cancer. Nutrients 11:2205. doi: 10.3390/nu11092205

Bensard, C. L., Wisidagama, D. R., Olson, K. A., Berg, J. A., Krah, N. M., Schell, J. C., et al. (2020). Regulation of tumor initiation by the mitochondrial Pyruvate Carrier. Cell Metab. 31, 284-300.e7.

Bhandari, R. K., Oda, R. P., Petrikovics, I., Thompson, D. E., Brenner, M., Mahon, S. B., et al. (2014). Cyanide toxicokinetics: the behavior of cyanide, thiocyanate and 2-amino-2-thiazoline-4-carboxylic acid in multiple animal models. J. Anal. Toxicol. 38, 218-225. doi: 10.1093/jat/bku020

Bose, S., and Le, A. (2018). Glucose metabolism in cancer. Adv. Exp. Med. Biol. 1063, 3-12.

Bosron, W. F., and Prairie, R. L. (1972). Triphosphopyridine nucleotide-linked aldehyde reductase. I. Purification and properties of the enzyme from pig kidney cortex. J. Biol. Chem. 247, 4480-4485.

Brunetti, P., Jourdian, G. W., and Roseman, S. (1962). The sialic acids. III. Distribution and properties of animal $\mathrm{N}$-acetylneuraminic aldolase. J. Biol. Chem. 237, 2447-2453.

Bukato, G., Kochan, Z., and Swierczynski, J. (1995). Purification and properties of cytosolic and mitochondrial malic enzyme isolated from human brain. Int. J. Biochem. Cell Biol. 27, 47-54. doi: 10.1016/1357-2725(94)00057-3

Bull, H., Murray, P. G., Thomas, D., Fraser, A. M., and Nelson, P. N. (2002). Acid phosphatases. Mol. Pathol. 55, 65-72.

Cammack, R. (1969). Assay, purification and properties of mammalian D-2hydroxy acid dehydrogenase. Biochem. J. 115, 55-64. doi: 10.1042/bj1150055

Cammack, R. (1970). Mammalian D-2-hydroxy acid dehydrogenase. Effect of inhibitors and reaction sequence. Biochem. J. 118, 405-408. doi: 10.1042/ bj1180405

Cao, S., Durrani, F. A., Toth, K., and Rustum, Y. M. (2014). Semethylselenocysteine offers selective protection against toxicity and potentiates the antitumour activity of anticancer drugs in preclinical animal models. $\mathrm{Br}$. J. Cancer 110, 1733-1743. doi: 10.1038/bjc.2014.85

Capala, M. E., Pruis, M., Vellenga, E., and Schuringa, J. J. (2016). Depletion of SAM50 Specifically Targets BCR-ABL-expressing leukemic stem and progenitor cells by interfering with mitochondrial functions. Stem Cells Dev. 25, 427-437. doi: $10.1089 / \mathrm{scd} .2015 .0151$

Carlsen, B. D., Lambeth, D. O., and Ray, P. D. (1988). Synthesis of malate from phosphoenolpyruvate by rabbit liver mitochondria: implications for lipogenesis. Biochim. Biophys. Acta 965, 1-8. doi: 10.1016/0304-4165(88) 90143-2

Carlson, G. M., Colombo, G., and Lardy, H. A. (1978). A vicinal dithiol containing an essential cysteine in phosphoenolpyruvate carboxykinase (guanosine triphosphate) from cytosol of rat liver. Biochemistry 17, 5329-5338. doi: 10 . 1021/bi00618a002

Castellano, F., and Molinier-Frenkel, V. (2017). An overview of l-amino acid oxidase functions from bacteria to mammals: focus on the immunoregulatory phenylalanine oxidase IL4I1. Molecules 22:2151. doi: 10.3390/molecules22122151

Chaneton, B., Hillmann, P., Zheng, L., Martin, A. C. L., Maddocks, O. D. K., Chokkathukalam, A., et al. (2012). Serine is a natural ligand and allosteric activator of pyruvate kinase M2. Nature 491, 458-462. doi: 10.1038/ nature 11540

Chao, T. Y., Yu, J. C., Ku, C. H., Chen, M. M., Lee, S. H., Janckila, A. J., et al. (2005). Tartrate-resistant acid phosphatase $5 \mathrm{~b}$ is a useful serum marker for extensive bone metastasis in breast cancer patients. Clin. Cancer Res. 11, 544-550.

Chen, C. H., and Chen, S. C. (1988). Evidence of acid phosphatase in the cytoplasm as a distinct entity. Arch. Biochem. Biophys. 262, 427-438. doi: 10.1016/00039861(88)90394-3

Chen, C. M., Chen, S. M., Chien, P. J., and Yu, H. Y. (2015). Development of an enzymatic assay system of D-lactate using D-lactate dehydrogenase and a UV-LED fluorescent spectrometer. J. Pharm. Biomed. Anal. 116, 150-155. doi: 10.1016/j.jpba.2015.07.018

Chiavarina, B., Nokin, M. J., Bellier, J., Durieux, F., Bletard, N., Sherer, F., et al. (2017). Methylglyoxal-mediated stress correlates with high metabolic activity and promotes tumor growth in colorectal cancer. Int. J. Mol. Sci. 18:213. doi: 10.3390/ijms18010213

Chiku, T., Padovani, D., Zhu, W., Singh, S., Vitvitsky, V., and Banerjee, R. (2009). $\mathrm{H} 2 \mathrm{~S}$ biogenesis by human cystathionine gamma-lyase leads to the novel sulfur metabolites lanthionine and homolanthionine and is responsive to the grade of hyperhomocysteinemia. J. Biol. Chem. 284, 11601-11612. doi: 10.1074/jbc. m808026200

Chinopoulos, C., Gerencser, A. A., Mandi, M., Mathe, K., Torocsik, B., Doczi, J., et al. (2010). Forward operation of adenine nucleotide translocase during F0F1ATPase reversal: critical role of matrix substrate-level phosphorylation. FASEB J. 24, 2405-2416. doi: 10.1096/fj.09-149898

Christofk, H. R., Vander Heiden, M. G., Harris, M. H., Ramanathan, A., Gerszten, R. E., Wei, R., et al. (2008). The M2 splice isoform of pyruvate kinase is important for cancer metabolism and tumour growth. Nature 452, 230-233. doi: $10.1038 /$ nature 06734

Chypre, M., Zaidi, N., and Smans, K. (2012). ATP-citrate lyase: a mini-review. Biochem. Biophys. Res. Commun. 422, 1-4. doi: 10.1016/j.bbrc.2012.04.144

Colilla, W., Jorgenson, R. A., and Nordlie, R. C. (1975). Mammalian carbamyl phosphate : glucose phosphotransferase and glucose-6-phosphate phosphohydrolase: extended tissue distribution. Biochim. Biophys. Acta 377, 117-125. doi: 10.1016/0005-2744(75)90292-2

Collins, M. A., Nijm, W. P., Borge, G. F., Teas, G., and Goldfarb, C. (1979). Dopamine-related tetrahydroisoquinolines: significant urinary excretion by alcoholics after alcohol consumption. Science 206, 1184-1186. doi: 10.1126/ science. 505002

Cooper, A. J. (1977). Asparagine transaminase from rat liver. J. Biol. Chem. 252, 2032-2038.

Cooper, A. J., Krasnikov, B. F., Niatsetskaya, Z. V., Pinto, J. T., Callery, P. S., Villar, M. T., et al. (2011). Cysteine S-conjugate beta-lyases: important roles in the metabolism of naturally occurring sulfur and selenium-containing compounds, xenobiotics and anticancer agents. Amino Acids 41, 7-27. doi: 10.1007/s00726010-0552-0

Cooper, A. J., and Kuhara, T. (2014). alpha-Ketoglutaramate: an overlooked metabolite of glutamine and a biomarker for hepatic encephalopathy and inborn errors of the urea cycle. Metab. Brain Dis. 29, 991-1006. doi: 10.1007/ s11011-013-9444-9

Cooper, A. J., and Pinto, J. T. (2006). Cysteine S-conjugate beta-lyases. Amino Acids 30, 1-15. doi: 10.1007/s00726-005-0243-4

Cooper, A. J., Raps, S. P., and Meister, A. (1987). Fluorometric determination of alpha-ketosuccinamic acid in rat tissues. Anal. Biochem. 167, 312-320. doi: 10.1016/0003-2697(87)90170-9

Cooper, J. L., and Meister, A. (1972). Isolation and properties of highly purified glutamine transaminase. Biochemistry 11, 661-671. doi: 10.1021/bi00755a001

Copper, A. J., and Meister, A. (1973). Enzymatic conversion of O-carbamyl-Lserine to pyruvate and ammonia. Biochem. Biophys. Res. Commun. 55, 780-787. doi: 10.1016/0006-291x(73)91212-6

Cordell, P. A., Futers, T. S., Grant, P. J., and Pease, R. J. (2004). The Human hydroxyacylglutathione hydrolase (HAGH) gene encodes both cytosolic and mitochondrial forms of glyoxalase II. J. Biol. Chem. 279, 28653-28661. doi: 10.1074/jbc.m403470200

Cortes-Cros, M., Hemmerlin, C., Ferretti, S., Zhang, J., Gounarides, J. S., Yin, H., et al. (2013). M2 isoform of pyruvate kinase is dispensable for tumor maintenance and growth. Proc. Natl. Acad. Sci. U.S.A. 110, 489-494. doi: 10.1073/pnas. 1212780110

D’Aniello, C., Patriarca, E. J., Phang, J. M., and Minchiotti, G. (2020). Proline metabolism in tumor growth and metastatic progression. Front. Oncol. 10:776. doi: 10.3389/fonc. 2020.00776

Danpure, C. J., Lumb, M. J., Birdsey, G. M., and Zhang, X. (2003). Alanine:glyoxylate aminotransferase peroxisome-to-mitochondrion mistargeting in human hereditary kidney stone disease. Biochim. Biophys. Acta 1647, 70-75. doi: 10.1016/s1570-9639(03)00055-4

Dawkins, P. D., and Dickens, F. (1965). The Oxidation of D- and L-Glycerate by Rat Liver. Biochem. J. 94, 353-367. doi: 10.1042/bj0940353

Dayton, T. L., Gocheva, V., Miller, K. M., Bhutkar, A., Lewis, C. A., Bronson, R. T., et al. (2018). Isoform-specific deletion of PKM2 constrains tumor initiation in a mouse model of soft tissue sarcoma. Cancer Metab. 6:6.

Dayton, T. L., Gocheva, V., Miller, K. M., Israelsen, W. J., Bhutkar, A., Clish, C. B., et al. (2016a). Germline loss of PKM2 promotes metabolic distress and 
hepatocellular carcinoma. Genes Dev. 30, 1020-1033. doi: 10.1101/gad.278549. 116

Dayton, T. L., Jacks, T., and Vander Heiden, M. G. (2016b). PKM2, cancer metabolism, and the road ahead. EMBO Rep. 17, 1721-1730.

de la Cruz-Lopez, K. G., Castro-Munoz, L. J., Reyes-Hernandez, D. O., GarciaCarranca, A., and Manzo-Merino, J. (2019). Lactate in the regulation of tumor microenvironment and therapeutic approaches. Front. Oncol. 9:1143. doi: 10. 3389/fonc.2019.01143

De Marchi, T., Timmermans, M. A., Sieuwerts, A. M., Smid, M., Look, M. P., Grebenchtchikov, N., et al. (2017). Phosphoserine aminotransferase 1 is associated to poor outcome on tamoxifen therapy in recurrent breast cancer. Sci. Rep. 7:2099.

DeBerardinis, R. J., Lum, J. J., Hatzivassiliou, G., and Thompson, C. B. (2008). The biology of cancer: metabolic reprogramming fuels cell growth and proliferation. Cell Metab. 7, 11-20. doi: 10.1016/j.cmet.2007.10.002

DeBerardinis, R. J., Mancuso, A., Daikhin, E., Nissim, I., Yudkoff, M., Wehrli, S., et al. (2007). Beyond aerobic glycolysis: transformed cells can engage in glutamine metabolism that exceeds the requirement for protein and nucleotide synthesis. Proc. Natl. Acad. Sci. U.S.A. 104, 19345-19350. doi: 10.1073/pnas. 0709747104

Dey, P., Baddour, J., Muller, F., Wu, C. C., Wang, H., Liao, W. T., et al. (2017). Genomic deletion of malic enzyme 2 confers collateral lethality in pancreatic cancer. Nature 542, 119-123. doi: 10.1038/nature21052

Dong, Y., Tu, R., Liu, H., and Qing, G. (2020). Regulation of cancer cell metabolism: oncogenic MYC in the driver's seat. Signal Transduct. Target. Ther. 5:124.

Drahota, Z., Rauchova, H., Mikova, M., Kaul, P., and Bass, A. (1983). Phosphoenolpyruvate shuttle-transport of energy from mitochondria to cytosol. FEBS Lett. 157, 347-349. doi: 10.1016/0014-5793(83)80573-0

Ducker, G. S., Ghergurovich, J. M., Mainolfi, N., Suri, V., Jeong, S. K., Hsin-Jung Li, S., et al. (2017). Human SHMT inhibitors reveal defective glycine import as a targetable metabolic vulnerability of diffuse large B-cell lymphoma. Proc. Natl. Acad. Sci. U.S.A. 114, 11404-11409. doi: 10.1073/pnas.1706617114

Eagle, H., Oyama, V. I., Levy, M., Horton, C. L., and Fleischman, R. (1956). The growth response of mammalian cells in tissue culture to L-glutamine and L-glutamic acid. J. Biol. Chem. 218, 607-616.

Elia, I., Broekaert, D., Christen, S., Boon, R., Radaelli, E., Orth, M. F., et al. (2017). Proline metabolism supports metastasis formation and could be inhibited to selectively target metastasizing cancer cells. Nat. Commun. 8:15267.

Erecinska, M., and Wilson, D. F. (1984). Relationship of the intra- and extramitochondrial adenine nucleotide ratios during synthesis of phosphoenolpyruvate using extramitochondrial ATP. J. Biol. Chem. 259, 10904-10906.

Esaki, N., Nakamura, T., Tanaka, H., and Soda, K. (1982). Selenocysteine lyase, a novel enzyme that specifically acts on selenocysteine. Mammalian distribution and purification and properties of pig liver enzyme. J. Biol. Chem. 257, 43864391.

Ewaschuk, J. B., Naylor, J. M., and Zello, G. A. (2005). D-lactate in human and ruminant metabolism. J. Nutr. 135, 1619-1625. doi: 10.1093/jn/135.7.1619

Feng, H., Wang, X., Chen, J., Cui, J., Gao, T., Gao, Y., et al. (2019). Nuclear imaging of glucose metabolism: beyond (18)F-FDG. Contrast Media Mol. Imaging 2019:7954854.

Finak, G., Bertos, N., Pepin, F., Sadekova, S., Souleimanova, M., Zhao, H., et al. (2008). Stromal gene expression predicts clinical outcome in breast cancer. Nat. Med. 14, 518-527.

Flick, M. J., and Konieczny, S. F. (2002). Identification of putative mammalian D-lactate dehydrogenase enzymes. Biochem. Biophys. Res. Commun. 295, 910 916. doi: $10.1016 / \mathrm{s} 0006-291 \mathrm{x}(02) 00768-4$

Fong, M. Y., McDunn, J., and Kakar, S. S. (2011). Identification of metabolites in the normal ovary and their transformation in primary and metastatic ovarian cancer. PLoS One 6:e19963. doi: 10.1371/journal.pone.001 9963

Fry, D. W., and Richardson, K. E. (1979). Isolation and characterization of glycolic acid oxidase from human liver. Biochim. Biophys. Acta 568, 135-144. doi: 10.1016/0005-2744(79)90281-x

Fuchs, S. A., Berger, R., Klomp, L. W., and de Koning, T. J. (2005). D-amino acids in the central nervous system in health and disease. Mol. Genet. Metab. 85, 168-180. doi: 10.1016/j.ymgme.2005.03.003
Garber, A. J., and Ballard, F. J. (1970). Regulation of phosphoenolpyruvate metabolism in mitochondria from guinea pig liver. J. Biol. Chem. 245, 22292240.

Garber, A. J., and Salganicoff, L. (1973). Regulation of oxalacetate metabolism in liver mitochondria. Evidence for nicotinamide adenine dinucleotidemalate dehydrogenase equilibrium and the role of phosphoenolpyruvate carboxykinase in the control of oxalacetate metabolism in intact guinea pig and rat liver mitochondria. J. Biol. Chem. 248, 1520-1529.

Garrow, T. A., Brenner, A. A., Whitehead, V. M., Chen, X. N., Duncan, R. G., Korenberg, J. R., et al. (1993). Cloning of human cDNAs encoding mitochondrial and cytosolic serine hydroxymethyltransferases and chromosomal localization. J. Biol. Chem. 268, 11910-11916.

Gavaret, J. M., Nunez, J., and Cahnmann, H. J. (1980). Formation of dehydroalanine residues during thyroid hormone synthesis in thyroglobulin. J. Biol. Chem. 255, 5281-5285.

Goto, Y., Shimizu, J., and Shukuya, R. (1980). Purification and molecular characteristics of mitochondrial phosphoenolpyruvate carboxykinase from bullfrog (Rana catesbeiana) liver. J. Biochem. 88, 1239-1249. doi: 10.1093/ oxfordjournals.jbchem.a133092

Guo, J. H., Hexige, S., Chen, L., Zhou, G. J., Wang, X., Jiang, J. M., et al. (2006). Isolation and characterization of the human D-glyceric acidemia related glycerate kinase gene GLYCTK1 and its alternatively splicing variant GLYCTK2. DNA Seq. 17, 1-7. doi: 10.1080/10425170500476665

Hall, A., Meyle, K. D., Lange, M. K., Klima, M., Sanderhoff, M., Dahl, C., et al. (2013). Dysfunctional oxidative phosphorylation makes malignant melanoma cells addicted to glycolysis driven by the (V600E)BRAF Oncogene. Oncotarget 4, 584-599. doi: 10.18632/oncotarget.965

Harris, R. A., and Fenton, A. W. (2019). A critical review of the role of M2PYK in the Warburg effect. Biochim. Biophys. Acta Rev. Cancer 1871, 225-239. doi: 10.1016/j.bbcan.2019.01.004

Hayman, A. R., Warburton, M. J., Pringle, J. A., Coles, B., and Chambers, T. J. (1989). Purification and characterization of a tartrate-resistant acid phosphatase from human osteoclastomas. Biochem. J. 261, 601-609. doi: 10.1042/bj2610601

Hebda, C. A., and Nowak, T. (1982). The purification, characterization, and activation of phosphoenolpyruvate carboxykinase from chicken liver mitochondria. J. Biol. Chem. 257, 5503-5514.

Helwig, J. J., Farooqui, A. A., Bollack, C., and Mandel, P. (1978). Purification and some properties of tartrate-sensitive acid phosphatase from rabbit kidney cortex. Biochem. J. 175, 321-329. doi: 10.1042/bj1750321

Hillis, A. L., Lau, A. N., Devoe, C. X., Dayton, T. L., Danai, L. V., Di Vizio, D., et al. (2018). PKM2 is not required for pancreatic ductal adenocarcinoma. Cancer Metab. 6:17.

Hirsch, H., and Greenberg, D. M. (1967). Studies on phosphoserine aminotransferase of sheep brain. J. Biol. Chem. 242, 2283-2287.

Holmes, R. P., and Assimos, D. G. (1998). Glyoxylate synthesis, and its modulation and influence on oxalate synthesis. J. Urol. 160, 1617-1624. doi: 10.1097/ 00005392-199811000-00003

Hong, C. S., Graham, N. A., Gu, W., Espindola Camacho, C., Mah, V., Maresh, E. L., et al. (2016). MCT1 Modulates Cancer Cell Pyruvate Export and Growth of Tumors that Co-express MCT1 and MCT4. Cell Rep. 14, 1590-1601. doi: 10.1016/j.celrep.2016.01.057

Hoshino, A., Hirst, J. A., and Fujii, H. (2007). Regulation of cell proliferation by interleu-induced nuclear translocation of pyruvate kinase. J. Biol. Chem. 282, 17706-17711. doi: 10.1074/jbc.m700094200

Hosios, A. M., Fiske, B. P., Gui, D. Y., and Vander Heiden, M. G. (2015). Lack of Evidence for PKM2 Protein Kinase Activity. Mol. Cell 59, 850-857. doi: 10.1016/j.molcel.2015.07.013

Hsu, M. C., and Hung, W. C. (2018). Pyruvate kinase M2 fuels multiple aspects of cancer cells: from cellular metabolism, transcriptional regulation to extracellular signaling. Mol. Cancer 17:35.

Hu, Y., Lu, W., Chen, G., Wang, P., Chen, Z., Zhou, Y., et al. (2012). K-ras(G12V) transformation leads to mitochondrial dysfunction and a metabolic switch from oxidative phosphorylation to glycolysis. Cell Res. 22, 399-412. doi: 10.1038/cr. 2011.145

Hussien, R., and Brooks, G. A. (2011). Mitochondrial and plasma membrane lactate transporter and lactate dehydrogenase isoform expression in breast cancer cell lines. Physiol. Genomics 43, 255-264. doi: 10.1152/physiolgenomics.00177.2010 
Icard, P., and Lincet, H. (2012). A global view of the biochemical pathways involved in the regulation of the metabolism of cancer cells. Biochim. Biophys. Acta 1826, 423-433. doi: 10.1016/j.bbcan.2012.07.001

Ip, C., Hayes, C., Budnick, R. M., and Ganther, H. E. (1991). Chemical form of selenium, critical metabolites, and cancer prevention. Cancer Res. 51, 595-600.

Israelsen, W. J., Dayton, T. L., Davidson, S. M., Fiske, B. P., Hosios, A. M., Bellinger, G., et al. (2013). PKM2 isoform-specific deletion reveals a differential requirement for pyruvate kinase in tumor cells. Cell 155, 397-409. doi: 10.1016/ j.cell.2013.09.025

Israelsen, W. J., and Vander Heiden, M. G. (2015). Pyruvate kinase: function, regulation and role in cancer. Semin. Cell Dev. Biol. 43, 43-51. doi: 10.1016/ j.semcdb.2015.08.004

Ito, S., Ohyama, T., Kontani, Y., Matslida, K., Sakata, S. F., and Tamaki, N. (2001). Influence of dietary protein levels on beta-alanine aminotransferase expression and activity in rats. J. Nutr. Sci. Vitaminol. 47, 275-282. doi: 10.3177/jnsv.47.275

Jeske, L., Placzek, S., Schomburg, I., Chang, A., and Schomburg, D. (2019). BRENDA in 2019: a European ELIXIR core data resource. Nucleic Acids Res. 47, D542-D549.

Jones, J. M., Morrell, J. C., and Gould, S. J. (2000). Identification and characterization of HAOX1, HAOX2, and HAOX3, three human peroxisomal 2-hydroxy acid oxidases. J. Biol. Chem. 275, 12590-12597. doi: 10.1074/jbc.275. 17.12590

Kakimoto, Y., Taniguchi, K., and Sano, I. (1969). D-betaaminoisobutyrate:pyruvate aminotransferase in mammalian liver and excretion of beta-aminoisobutyrate by man. J. Biol. Chem. 244, 335-340.

Kanehisa, M., and Goto, S. (2000). KEGG: kyoto encyclopedia of genes and genomes. Nucleic Acids Res. 28, 27-30.

Kashii, T., Gomi, T., Oya, T., Ishii, Y., Oda, H., Maruyama, M., et al. (2005). Some biochemical and histochemical properties of human liver serine dehydratase. Int. J. Biochem. Cell Biol. 37, 574-589. doi: 10.1016/j.biocel.2004.08.004

Kim, M. J., and Whitesides, G. M. (1988). L-Lactate dehydrogenase: substrate specificity and use as a catalyst in the synthesis of homochiral 2-hydroxy acids. J. Am. Chem. Soc. 110, 2959-2964. doi: 10.1021/ja00217a044

King, Z. A., Lu, J., Drager, A., Miller, P., Federowicz, S., Lerman, J. A., et al. (2016). BiGG Models: a platform for integrating, standardizing and sharing genome-scale models. Nucleic Acids Res. 44, D515-D522.

Kleineke, J., Sauer, H., and Soling, H. D. (1973). On the specificity of the tricarboxylate carrier system in rat liver mitochondria. FEBS Lett. 29, 82-86. doi: 10.1016/0014-5793(73)80531-9

Knott, S. R. V., Wagenblast, E., Khan, S., Kim, S. Y., Soto, M., Wagner, M., et al. (2018). Asparagine bioavailability governs metastasis in a model of breast cancer. Nature 554, 378-381. doi: 10.1038/nature25465

Koizumi, M., and Ogata, E. (2002). Bone metabolic markers as gauges of metastasis to bone: a review. Ann. Nucl. Med. 16, 161-168. doi: 10.1007/bf02996296

Koseki, J., Konno, M., Asai, A., Colvin, H., Kawamoto, K., Nishida, N., et al. (2018). Enzymes of the one-carbon folate metabolism as anticancer targets predicted by survival rate analysis. Sci. Rep. 8:303.

Krall, A. S., Xu, S., Graeber, T. G., Braas, D., and Christofk, H. R. (2016). Asparagine promotes cancer cell proliferation through use as an amino acid exchange factor. Nat. Commun. 7:11457.

Krebs, H. A., and Johnson, W. A. (1937). Acetopyruvic acid (alphagammadiketovaleric acid) as an intermediate metabolite in animal tissues. Biochem. J. 31, 772-779. doi: 10.1042/bj0310772

Lambrecht, J. A., Flynn, J. M., and Downs, D. M. (2012). Conserved YjgF protein family deaminates reactive enamine/imine intermediates of pyridoxal 5'-phosphate (PLP)-dependent enzyme reactions. J. Biol. Chem. 287, 34543461. doi: 10.1074/jbc.m111.304477

Lange, J. N., Wood, K. D., Knight, J., Assimos, D. G., and Holmes, R. P. (2012). Glyoxal formation and its role in endogenous oxalate synthesis. Adv. Urol. 2012:819202.

Lau, A. N., Israelsen, W. J., Roper, J., Sinnamon, M. J., Georgeon, L., Dayton, T. L., et al. (2017). PKM2 is not required for colon cancer initiated by APC loss. Cancer Metab. 5:10.

Le, A., Lane, A. N., Hamaker, M., Bose, S., Gouw, A., Barbi, J., et al. (2012). Glucose-independent glutamine metabolism via TCA cycling for proliferation and survival in B cells. Cell Metab. 15, 110-121. doi: 10.1016/j.cmet.2011.12.009

Lee, I. S., Muragaki, Y., Ideguchi, T., Hase, T., Tsuji, M., Ooshima, A., et al. (1995). Molecular cloning and sequencing of a cDNA encoding alanine-glyoxylate aminotransferase 2 from rat kidney. J. Biochem. 117, 856-862. doi: 10.1093/ oxfordjournals.jbchem.a124787

Leithner, K., Hrzenjak, A., Trotzmuller, M., Moustafa, T., Kofeler, H. C., Wohlkoenig, C., et al. (2015). PCK2 activation mediates an adaptive response to glucose depletion in lung cancer. Oncogene 34, 1044-1050. doi: 10.1038/onc. 2014.47

Li, X., and Peng, S. (2013). Identification of metastasis-associated genes in colorectal cancer through an integrated genomic and transcriptomic analysis. Chin. J. Cancer Res. 25, 623-636.

Li, Y. H., Li, X. F., Liu, J. T., Wang, H., Fan, L. L., Li, J., et al. (2018). PKM2, a potential target for regulating cancer. Gene 668, 48-53. doi: 10.1016/j.gene. 2018.05.038

Li, Z., Yang, P., and Li, Z. (2014). The multifaceted regulation and functions of PKM2 in tumor progression. Biochim. Biophys. Acta 1846, 285-296. doi: 10.1016/j.bbcan.2014.07.008

Lieu, E. L., Nguyen, T., Rhyne, S., and Kim, J. (2020). Amino acids in cancer. Exp. Mol. Med. 52, 15-30.

Liu, B., Jia, Y., Cao, Y., Wu, S., Jiang, H., Sun, X., et al. (2016). Overexpression of Phosphoserine Aminotransferase 1 (PSAT1) Predicts Poor Prognosis and Associates with Tumor Progression in Human Esophageal Squamous Cell Carcinoma. Cell. Physiol. Biochem. 39, 395-406. doi: 10.1159/000445633

Liu, C., Cao, J., Lin, S., Zhao, Y., Zhu, M., Tao, Z., et al. (2020). Malic enzyme 1 indicates worse prognosis in breast cancer and promotes metastasis by manipulating reactive oxygen species. Onco Targets Ther. 13, 8735-8747. doi: 10.2147/ott.s256970

Liu, P., Ge, X., Ding, H., Jiang, H., Christensen, B. M., and Li, J. (2012). Role of glutamate decarboxylase-like protein 1 (GADL1) in taurine biosynthesis. J. Biol. Chem. 287, 40898-40906. doi: 10.1074/jbc.m112.393728

Liu, V. M., Howell, A. J., Hosios, A. M., Li, Z., Israelsen, W. J., and Vander Heiden, M. G. (2020). Cancer-associated mutations in human pyruvate kinase M2 impair enzyme activity. FEBS Lett. 594, 646-664. doi: 10.1002/1873-3468.13648

Loeber, G., Dworkin, M. B., Infante, A., and Ahorn, H. (1994). Characterization of cytosolic malic enzyme in human tumor cells. FEBS Lett. 344, 181-186. doi: 10.1016/0014-5793(94)00386-6

Lunt, S. Y., Muralidhar, V., Hosios, A. M., Israelsen, W. J., Gui, D. Y., Newhouse, L., et al. (2015). Pyruvate kinase isoform expression alters nucleotide synthesis to impact cell proliferation. Mol. Cell 57, 95-107. doi: 10.1016/j.molcel.2014.10. 027

Luo, W., Hu, H., Chang, R., Zhong, J., Knabel, M., O’Meally, R., et al. (2011). Pyruvate kinase M2 is a PHD3-stimulated coactivator for hypoxia-inducible factor 1. Cell 145, 732-744. doi: 10.1016/j.cell.2011.03.054

Lv, L., Li, D., Zhao, D., Lin, R., Chu, Y., Zhang, H., et al. (2011). Acetylation targets the M2 isoform of pyruvate kinase for degradation through chaperonemediated autophagy and promotes tumor growth. Mol. Cell 42, 719-730. doi: 10.1016/j.molcel.2011.04.025

Makinen, A. L., and Nowak, T. (1983). 3-Mercaptopicolinate. A reversible active site inhibitor of avian liver phosphoenolpyruvate carboxykinase. J. Biol. Chem. 258, 11654-11662.

Matoba, S., Kang, J. G., Patino, W. D., Wragg, A., Boehm, M., Gavrilova, O., et al. (2006). p53 regulates mitochondrial respiration. Science 312, 1650-1653. doi: $10.1126 /$ science. 1126863

Maul, D. M., and Schuster, S. M. (1986). Kinetic properties and characteristics of mouse liver mitochondrial asparagine aminotransferase. Arch. Biochem. Biophys. 251, 585-593. doi: 10.1016/0003-9861(86)90367-x

Mayers, J. R., Torrence, M. E., Danai, L. V., Papagiannakopoulos, T., Davidson, S. M., Bauer, M. R., et al. (2016). Tissue of origin dictates branched-chain amino acid metabolism in mutant Kras-driven cancers. Science 353, 1161-1165. doi: 10.1126/science.aaf5171

Mazurek, S., Boschek, C. B., Hugo, F., and Eigenbrodt, E. (2005). Pyruvate kinase type M2 and its role in tumor growth and spreading. Semin. Cancer Biol. 15, 300-308. doi: 10.1016/j.semcancer.2005.04.009

McKeehan, W. L. (1982). Glycolysis, glutaminolysis and cell proliferation. Cell Biol. Int. Rep. 6, 635-650. doi: 10.1016/0309-1651(82)90125-4

Mdluli, K., Booth, M. P., Brady, R. L., and Rumsby, G. (2005). A preliminary account of the properties of recombinant human Glyoxylate reductase (GRHPR), LDHA and LDHB with glyoxylate, and their potential roles in its metabolism. Biochim. Biophys. Acta 1753, 209-216. doi: 10.1016/j.bbapap.2005. 08.004 
Medina, D., Thompson, H., Ganther, H., and Ip, C. (2001). Semethylselenocysteine: a new compound for chemoprevention of breast cancer. Nutr. Cancer 40, 12-17. doi: 10.4324/9781410608000-4

Metcalf, S., Dougherty, S., Kruer, T., Hasan, N., Biyik-Sit, R., Reynolds, L., et al. (2020). Selective loss of phosphoserine aminotransferase 1 (PSAT1) suppresses migration, invasion, and experimental metastasis in triple negative breast cancer. Clin. Exp. Metastasis 37, 187-197. doi: 10.1007/s10585-019-10000-7

Michelakis, E. D., Webster, L., and Mackey, J. R. (2008). Dichloroacetate (DCA) as a potential metabolic-targeting therapy for cancer. Br. J. Cancer 99, 989-994. doi: $10.1038 /$ sj.bjc.6604554

Mills, E. L., Kelly, B., Logan, A., Costa, A. S. H., Varma, M., Bryant, C. E., et al. (2016). Succinate Dehydrogenase supports metabolic repurposing of mitochondria to drive inflammatory macrophages. Cell 167, 457-470.e13.

Minatogawa, Y., Noguchi, T., and Kido, R. (1977). Species distribution and properties of hepatic phenylalanine (histidine):pyruvate aminotransferase. Hoppe Seylers Z. Physiol. Chem. 358, 59-67. doi: 10.1515/bchm2.1977.358.1.59

Moreno-Sanchez, R., Marin-Hernandez, A., Gallardo-Perez, J. C., PachecoVelazquez, S. C., Robledo-Cadena, D. X., Padilla-Flores, J. A., et al. (2020). Physiological Role of Glutamate Dehydrogenase in Cancer Cells. Front. Oncol. 10:429. doi: 10.3389/fonc.2020.00429

Moretti, S., Martin, O., Van Du Tran, T., Bridge, A., Morgat, A., and Pagni, M. (2016). MetaNetX/MNXref-reconciliation of metabolites and biochemical reactions to bring together genome-scale metabolic networks. Nucleic Acids Res. 44, D523-D526.

Mose, S., Menzel, C., Kurth, A. A., Obert, K., Breidert, I., Borowsky, K., et al. (2003). Tartrate-resistant acid phosphatase $5 \mathrm{~b}$ as serum marker of bone metabolism in cancer patients. Anticancer Res. 23, 2783-2788.

Murai, S., Ando, A., Ebara, S., Hirayama, M., Satomi, Y., and Hara, T. (2017). Inhibition of malic enzyme 1 disrupts cellular metabolism and leads to vulnerability in cancer cells in glucose-restricted conditions. Oncogenesis 6:e329. doi: 10.1038/oncsis.2017.34

Murata, M., Midorikawa, K., and Kawanishi, S. (2016). "Chapter 25 - Molecular Link Between Alcohol and Breast Cancer: the Role of Salsolinol," in Molecular Aspects of Alcohol and Nutrition, ed. V. B. Patel (San Diego, CA: Academic Press), 315-324. doi: 10.1016/b978-0-12-800773-0.00025-2

Nagahara, N., and Sawada, N. (2006). The mercaptopyruvate pathway in cysteine catabolism: a physiologic role and related disease of the multifunctional 3mercaptopyruvate sulfurtransferase. Curr. Med. Chem. 13, 1219-1230. doi: 10.2174/092986706776360914

Nagasawa, T., Ishii, T., Kumagai, H., and Yamada, H. (1985). D-Cysteine desulfhydrase of Escherichia coli. Purification and characterization. Eur. J. Biochem. 153, 541-551. doi: 10.1111/j.1432-1033.1985.tb09335.x

Nagata, Y., Masui, R., and Akino, T. (1992). The presence of free D-serine, D-alanine and D-proline in human plasma. Experientia 48, 986-988.

Nagayama, H., Muramatsu, M., and Shimura, K. (1958). Enzymatic formation of aminomalonic acid from ketomalonic acid. Nature 181, 417-418. doi: 10.1038/ $181417 \mathrm{a} 0$

Nakano, M., Tsutsumi, Y., and Danowski, T. S. (1967). Crystalline L-amino-acid oxidase from the soluble fraction of rat-kidney cells. Biochim. Biophys. Acta 139, 40-48. doi: 10.1016/0005-2744(67)90111-8

Nakashima, C., Kirita, T., Yamamoto, K., Mori, S., Luo, Y., Sasaki, T., et al. (2020). Malic enzyme 1 is associated with tumor budding in oral squamous cell carcinomas. Int. J. Mol. Sci. 21:7149. doi: 10.3390/ijms21197149

Nemeth, B., Doczi, J., Csete, D., Kacso, G., Ravasz, D., Adams, D., et al. (2016). Abolition of mitochondrial substrate-level phosphorylation by itaconic acid produced by LPS-induced Irg1 expression in cells of murine macrophage lineage. FASEB J. 30, 286-300. doi: 10.1096/fj.15-279398

Newman, A. C., and Maddocks, O. D. K. (2017). Serine and functional metabolites in cancer. Trends Cell Biol. 27, 645-657. doi: 10.1016/j.tcb.2017.05.001

Nguyen, M., Bonneterre, J., Hecquet, B., Desoize, B., and Demaille, A. (1991). Plasma acid and alkaline phosphatase in patients with breast cancer. Anticancer Res. 11, 831-833.

Nicolay, B. N., Danielian, P. S., Kottakis, F., Lapek, J. D. Jr., Sanidas, I., Miles, W. O., et al. (2015). Proteomic analysis of pRb loss highlights a signature of decreased mitochondrial oxidative phosphorylation. Genes Dev. 29, 1875-1889. doi: 10.1101/gad.264127.115

Nokin, M. J., Bellier, J., Durieux, F., Peulen, O., Rademaker, G., Gabriel, M., et al. (2019). Methylglyoxal, a glycolysis metabolite, triggers metastasis through
MEK/ERK/SMAD1 pathway activation in breast cancer. Breast Cancer Res. $21: 11$.

Nordlie, R. C. (1974). Metabolic regulation by multifunctional glucose-6phosphatase. Curr. Top. Cell. Regul. 8, 33-117. doi: 10.1016/b978-0-12152808-9.50009-2

Noronha, A., Modamio, J., Jarosz, Y., Guerard, E., Sompairac, N., Preciat, G., et al. (2019). The Virtual Metabolic Human database: integrating human and gut microbiome metabolism with nutrition and disease. Nucleic Acids Res. 47, D614-D624.

Ogawa, H., Gomi, T., Nishizawa, M., Hayakawa, Y., Endo, S., Hayashi, K., et al. (2006). Enzymatic and biochemical properties of a novel human serine dehydratase isoform. Biochim. Biophys. Acta 1764, 961-971. doi: 10.1016/j. bbapap.2006.02.010

Omura, H., Shimamura, M., and Yamafuji, K. (1956). Measurement of transoximase action. Enzymologia 17, 359-362.

Orywal, K., and Szmitkowski, M. (2017). Alcohol dehydrogenase and aldehyde dehydrogenase in malignant neoplasms. Clin. Exp. Med. 17, 131-139. doi: 10.1007/s10238-016-0408-3

Pallini, R., Guazzi, G. C., Cannella, C., and Cacace, M. G. (1991). Cloning and sequence analysis of the human liver rhodanese: comparison with the bovine and chicken enzymes. Biochem. Biophys. Res. Commun. 180, 887-893. doi: 10.1016/s0006-291x(05)81148-9

Panosyan, E. H., Wang, Y., Xia, P., Lee, W. N., Pak, Y., Laks, D. R., et al. (2014). Asparagine depletion potentiates the cytotoxic effect of chemotherapy against brain tumors. Mol. Cancer Res. 12, 694-702. doi: 10.1158/1541-7786.mcr-130576

Paone, A., Marani, M., Fiascarelli, A., Rinaldo, S., Giardina, G., Contestabile, R., et al. (2014). SHMT1 knockdown induces apoptosis in lung cancer cells by causing uracil misincorporation. Cell Death Dis. 5:e1525. doi: 10.1038/cddis. 2014.482

Passarella, S., Atlante, A., Valenti, D., and de Bari, L. (2003). The role of mitochondrial transport in energy metabolism. Mitochondrion 2, 319-343. doi: 10.1016/s1567-7249(03)00008-4

Pastuszak, I., Drake, R., and Elbein, A. D. (1996). Kidney N-acetylgalactosamine (GalNAc)-1-phosphate kinase, a new pathway of GalNAc activation. J. Biol. Chem. 271, 20776-20782. doi: 10.1074/jbc.271.34.20776

Petit, M., Koziel, R., Etemad, S., Pircher, H., and Jansen-Durr, P. (2017). Depletion of oxaloacetate decarboxylase FAHD1 inhibits mitochondrial electron transport and induces cellular senescence in human endothelial cells. Exp. Gerontol. 92, 7-12. doi: 10.1016/j.exger.2017.03.004

Phang, J. M. (2019). Proline metabolism in cell regulation and cancer biology: recent advances and hypotheses. Antioxid. Redox Signal. 30, 635-649. doi: 10.1089/ars.2017.7350

Pinthong, C., Maenpuen, S., Amornwatcharapong, W., Yuthavong, Y., Leartsakulpanich, U., and Chaiyen, P. (2014). Distinct biochemical properties of human serine hydroxymethyltransferase compared with the Plasmodium enzyme: implications for selective inhibition. FEBS J. 281, 2570-2583. doi: $10.1111 /$ febs. 12803

Pircher, H., Straganz, G. D., Ehehalt, D., Morrow, G., Tanguay, R. M., and Jansen-Durr, P. (2011). Identification of human fumarylacetoacetate hydrolase domain-containing protein 1 (FAHD1) as a novel mitochondrial acylpyruvase. J. Biol. Chem. 286, 36500-36508. doi: 10.1074/jbc.m111.264770

Pircher, H., von Grafenstein, S., Diener, T., Metzger, C., Albertini, E., Taferner, A., et al. (2015). Identification of FAH domain-containing protein 1 (FAHD1) as oxaloacetate decarboxylase. J. Biol. Chem. 290, 6755-6762. doi: 10.1074/jbc. m114.609305

Poore, R. E., Hurst, C. H., Assimos, D. G., and Holmes, R. P. (1997). Pathways of hepatic oxalate synthesis and their regulation. Am. J. Physiol. 272, C289-C294.

Prakasam, G., Iqbal, M. A., Bamezai, R. N. K., and Mazurek, S. (2018). Posttranslational Modifications of Pyruvate Kinase M2: tweaks that benefit cancer. Front. Oncol. 8:22. doi: 10.3389/fonc.2018. 00022

Reitzer, L. J., Wice, B. M., and Kennell, D. (1979). Evidence that glutamine, not sugar, is the major energy source for cultured HeLa cells. J. Biol. Chem. 254, 2669-2676.

Ren, J. G., Seth, P., Clish, C. B., Lorkiewicz, P. K., Higashi, R. M., Lane, A. N., et al. (2014). Knockdown of malic enzyme 2 suppresses lung tumor growth, induces differentiation and impacts PI3K/AKT signaling. Sci. Rep. 4:5414. 
Richarme, G., and Dairou, J. (2017). Parkinsonism-associated protein DJ-1 is a bona fide deglycase. Biochem. Biophys. Res. Commun. 483, 387-391. doi: 10. 1016/j.bbrc.2016.12.134

Richarme, G., Mihoub, M., Dairou, J., Bui, L. C., Leger, T., and Lamouri, A. (2015). Parkinsonism-associated protein DJ-1/Park7 is a major protein deglycase that repairs methylglyoxal- and glyoxal-glycated cysteine, arginine, and lysine residues. J. Biol. Chem. 290, 1885-1897. doi: 10.1074/jbc.m114.597815

Robinson, B. H. (1971). Transport of phosphoenolpyruvate by the tricarboxylate transporting system in mammalian mitochondria. FEBS Lett. 14, 309-312. doi: 10.1016/0014-5793(71)80287-9

Robinson, J. L., Kocabas, P., Wang, H., Cholley, P. E., Cook, D., Nilsson, A., et al. (2020). An atlas of human metabolism. Sci. Signal. 13:eaaz1482.

Rowsell, E. V. (1956). Transaminations with pyruvate and other alpha-keto acids. Biochem. J. 64, 246-252. doi: 10.1042/bj0640246

Sandler, M., Carter, S. B., Hunter, K. R., and Stern, G. M. (1973). Tetrahydroisoquinoline alkaloids: in vivo metabolites of L-dopa in man. Nature 241, 439-443. doi: 10.1038/241439a0

Satrustegui, J., Pardo, B., and Del Arco, A. (2007). Mitochondrial transporters as novel targets for intracellular calcium signaling. Physiol. Rev. 87, 29-67. doi: 10.1152/physrev.00005.2006

Sauer, L. A. (1973). An NAD- and NADP-dependent malic enzyme with regulatory properties in rat liver and adrenal cortex mitochondrial fractions. Biochem. Biophys. Res. Commun. 50, 524-531. doi: 10.1016/0006-291x(73)90871-1

Schadewaldt, P., Wendel, U., and Hammen, H. W. (1995). Human branched-chain L-amino acid aminotransferase: activity and subcellular localization in cultured skin fibroblasts. Amino Acids 9, 147-160.

Scott, D. A., Richardson, A. D., Filipp, F. V., Knutzen, C. A., Chiang, G. G., Ronai, Z. A., et al. (2011). Comparative metabolic flux profiling of melanoma cell lines: beyond the Warburg effect. J. Biol. Chem. 286, 42626-42634. doi: $10.1074 /$ jbc.m111.282046

Serpa, J. (2020). Cysteine as a Carbon Source, a Hot Spot in Cancer Cells Survival. Front. Oncol. 10:947. doi: 10.3389/fonc.2020.00947

Shan, Y., Gao, Y., Jin, W., Fan, M., Wang, Y., Gu, Y., et al. (2019). Targeting HIBCH to reprogram valine metabolism for the treatment of colorectal cancer. Cell Death Dis. 10, 618 .

Shapiro, R. A., Clark, V. M., and Curthoys, N. P. (1979). Inactivation of rat renal phosphate-dependent glutaminase with 6-diazo-5-oxo-L-norleucine. Evidence for interaction at the glutamine binding site. J. Biol. Chem. 254, 2835-2838.

Shen, H., Campanello, G. C., Flicker, D., Grabarek, Z., Hu, J., Luo, C., et al. (2017). The human knockout gene CLYBL connects Itaconate to Vitamin B12. Cell 171, 771-782.e11.

Shibuya, N., Koike, S., Tanaka, M., Ishigami-Yuasa, M., Kimura, Y., Ogasawara, Y., et al. (2013). A novel pathway for the production of hydrogen sulfide from D-cysteine in mammalian cells. Nat. Commun. 4:1366.

Shug, A. L., and Shrago, E. (1973). Inhibition of phosphoenolpyruvate transport via the tricarboxylate and adenine nucleotide carrier systems of rat liver mitochondria. Biochem. Biophys. Res. Commun. 53, 659-665. doi: 10.1016/ 0006-291x(73)90712-2

Silverstein, E. (1974). Equilibrium kinetic study of bovine liver glutamate dehydrogenase at high pH. Biochemistry 13, 3750-3754. doi: 10.1021/ bi00715a021

Smith, A. L., Whitehall, J. C., Bradshaw, C., Gay, D., Robertson, F., Blain, A. P., et al. (2020). Age-associated mitochondrial DNA mutations cause metabolic remodelling that contributes to accelerated intestinal tumorigenesis. Nat. Cancer 1, 976-989. doi: 10.1038/s43018-020-00112-5

Smith, S. M., Uslaner, J. M., Yao, L., Mullins, C. M., Surles, N. O., Huszar, S. L., et al. (2009). The behavioral and neurochemical effects of a novel D-amino acid oxidase inhibitor compound 8 [4H-thieno [3,2-b]pyrrole-5-carboxylic acid] and D-serine. J. Pharmacol. Exp. Ther. 328, 921-930. doi: 10.1124/jpet.108. 147884

Snell, K., Natsumeda, Y., Eble, J. N., Glover, J. L., and Weber, G. (1988). Enzymic imbalance in serine metabolism in human colon carcinoma and rat sarcoma. Br. J. Cancer 57, 87-90. doi: 10.1038/bjc.1988.15

Soda, K., and Osumi, T. (1969). Crystalline amino acid racemase with low substrate specificity. Biochem. Biophys. Res. Commun. 35, 363-368. doi: 10.1016/0006291x(69)90507-5

Soling, H. D., Walter, U., Sauer, H., and Kleineke, J. (1971). Effects of synthetic analogues of phosphoenolpyruvate on muscle and liver pyruvate kinase, muscle enolase, liver phosphoenolpyruvate carboxykinase and on the intra-/extramitochondrial tricarboxylic acid carrier transport system. FEBS Lett. 19, 139143. doi: 10.1016/0014-5793(71)80498-2

Son, J., Lyssiotis, C. A., Ying, H., Wang, X., Hua, S., Ligorio, M., et al. (2013). Glutamine supports pancreatic cancer growth through a KRAS-regulated metabolic pathway. Nature 496, 101-105. doi: 10.1038/nature12040

Stark, R., Pasquel, F., Turcu, A., Pongratz, R. L., Roden, M., Cline, G. W., et al. (2009). Phosphoenolpyruvate cycling via mitochondrial phosphoenolpyruvate carboxykinase links anaplerosis and mitochondrial GTP with insulin secretion. J. Biol. Chem. 284, 26578-26590. doi: 10.1074/jbc.m109.011775

Stetak, A., Veress, R., Ovadi, J., Csermely, P., Keri, G., and Ullrich, A. (2007). Nuclear translocation of the tumor marker pyruvate kinase M2 induces programmed cell death. Cancer Res. 67, 1602-1608. doi: 10.1158/0008-5472. can-06-2870

Stipanuk, M. H. (1979). Effect of excess dietary methionine on the catabolism of cysteine in rats. J. Nutr. 109, 2126-2139. doi: 10.1093/jn/109.12.2126

Stipanuk, M. H. (2020). Metabolism of Sulfur-Containing Amino Acids: how the Body Copes with Excess Methionine, Cysteine, and Sulfide. J. Nutr. 150(Suppl. 1), 2494S-2505S.

Stipanuk, M. H., Dominy, J. E. Jr., Lee, J. I., and Coloso, R. M. (2006). Mammalian cysteine metabolism: new insights into regulation of cysteine metabolism. J. Nutr. 136(6 Suppl.), 1652S-1659S.

Sul, H. S., Shrago, E., and Shug, A. L. (1976). Relationship of phosphoenolpyruvate transport, acyl coenzyme A inhibition of adenine nucleotide translocase and calcium ion efflux in guinea pig heart mitochondria. Arch. Biochem. Biophys. 172, 230-237. doi: 10.1016/0003-9861(76)90071-0

Sun, Y., Li, W., Shen, S., Yang, X., Lu, B., Zhang, X., et al. (2019). Loss of alanineglyoxylate and serine-pyruvate aminotransferase expression accelerated the progression of hepatocellular carcinoma and predicted poor prognosis. J. Transl. Med. 17:390.

Swick, R. W., and Wood, H. G. (1960). The Role of Transcarboxylation in Propionic Acid Fermentation. Proc. Natl. Acad. Sci. U.S.A. 46, 28-41. doi: 10.1073/pnas.46.1.28

Ta, N. L., and Seyfried, T. N. (2015). Influence of Serum and Hypoxia on Incorporation of $[(14) \mathrm{C}]-\mathrm{D}-\mathrm{Glucose}$ or [(14)C]-L-Glutamine into Lipids and Lactate in Murine Glioblastoma Cells. Lipids 50, 1167-1184. doi: 10.1007/ s11745-015-4075-z

Tech, K., Tikunov, A. P., Farooq, H., Morrissy, A. S., Meidinger, J., Fish, T., et al. (2017). Pyruvate Kinase Inhibits Proliferation during Postnatal Cerebellar Neurogenesis and Suppresses Medulloblastoma Formation. Cancer Res. 77, 3217-3230. doi: 10.1158/0008-5472.can-16-3304

Terpos, E., de la Fuente, J., Szydlo, R., Hatjiharissi, E., Viniou, N., Meletis, J., et al. (2003). Tartrate-resistant acid phosphatase isoform 5b: a novel serum marker for monitoring bone disease in multiple myeloma. Int. J. Cancer 106, 455-457. doi: 10.1002/ijc.11247

Thakur, A., Bollig, A., Wu, J., and Liao, D. J. (2008). Gene expression profiles in primary pancreatic tumors and metastatic lesions of Ela-c-myc transgenic mice. Mol. Cancer 7:11. doi: 10.1186/1476-4598-7-11

Thornalley, P. J. (1990). The glyoxalase system: new developments towards functional characterization of a metabolic pathway fundamental to biological life. Biochem. J. 269, 1-11. doi: 10.1042/bj2690001

Tsun, Z. Y., and Possemato, R. (2015). Amino acid management in cancer. Semin. Cell Dev. Biol. 43, 22-32.

Tudball, N., and Thomas, P. (1972). The enzymic degradation of L-serine O-sulphate, Mechanism of the reaction. Biochem. J. 128, 41-46. doi: 10.1042/ bj1280041

Vander Heiden, M. G., Cantley, L. C., and Thompson, C. B. (2009). Understanding the Warburg effect: the metabolic requirements of cell proliferation. Science 324, 1029-1033. doi: 10.1126/science.1160809

Vander Heiden, M. G., Locasale, J. W., Swanson, K. D., Sharfi, H., Heffron, G. J., Amador-Noguez, D., et al. (2010). Evidence for an alternative glycolytic pathway in rapidly proliferating cells. Science 329, 1492-1499. doi: 10.1126/ science. 1188015

Vander Jagt, D. L., and Hunsaker, L. A. (2003). Methylglyoxal metabolism and diabetic complications: roles of aldose reductase, glyoxalase-I, betaine aldehyde dehydrogenase and 2-oxoaldehyde dehydrogenase. Chem. Biol. Interact. 14, 341-351. doi: 10.1016/s0009-2797(02)00 212-0 
Vasseur, S., Afzal, S., Tardivel-Lacombe, J., Park, D. S., Iovanna, J. L., and Mak, T. W. (2009). DJ-1/PARK7 is an important mediator of hypoxia-induced cellular responses. Proc. Natl. Acad. Sci. U.S.A. 106, 1111-1116. doi: 10.1073/ pnas.0812745106

Vignaud, C., Pietrancosta, N., Williams, E. L., Rumsby, G., and Lederer, F. (2007). Purification and characterization of recombinant human liver glycolate oxidase. Arch. Biochem. Biophys. 465, 410-416. doi: 10.1016/j.abb.2007.06.021

Vincent, E. E., Sergushichev, A., Griss, T., Gingras, M. C., Samborska, B., Ntimbane, T., et al. (2015). Mitochondrial phosphoenolpyruvate carboxykinase regulates metabolic adaptation and enables glucose-independent tumor growth. Mol. Cell 60, 195-207. doi: 10.1016/j.molcel.2015.08.013

Wang, Y. H., Huang, J. T., Chen, W. L., Wang, R. H., Kao, M. C., Pan, Y. R., et al. (2019). Dysregulation of cystathionine gamma-lyase promotes prostate cancer progression and metastasis. EMBO Rep. 20:e45986.

Wang, Y. H., Israelsen, W. J., Lee, D., Yu, V. W. C., Jeanson, N. T., Clish, C. B., et al. (2014). Cell-state-specific metabolic dependency in hematopoiesis and leukemogenesis. Cell 158, 1309-1323. doi: 10.1016/j.cell.2014.07.048

Warren, L. (1986). Sialic acid lyase in human promyelocytic leukemic cells (HL60) during phorbol-ester-induced differentiation. Biochim. Biophys. Acta 888, 278-281. doi: 10.1016/0167-4889(86)90226-0

Weber, G. (1969). Inhibition of human brain pyruvate kinase and hexokinase by phenylalanine and phenylpyruvate: possible relevance to phenylketonuric brain damage. Proc. Natl. Acad. Sci. U.S.A. 63, 1365-1369. doi: 10.1073/pnas.63.4. 1365

Weber, G., and Cantero, A. (1955). Glucose-6-phosphatase activity in normal, pre-cancerous, and neoplastic tissues. Cancer Res. 15, 105-108.

Wiese, T. J., Wuensch, S. A., and Ray, P. D. (1996). Synthesis of citrate from phosphoenolpyruvate and acetylcarnitine by mitochondria from rabbit, pigeon and rat liver: implications for lipogenesis. Comp. Biochem. Physiol. B Biochem. Mol. Biol. 114, 417-422. doi: 10.1016/0305-0491(96)00035-1

Wilson, D. F., Erecinska, M., and Schramm, V. L. (1983). Evaluation of the relationship between the intra- and extramitochondrial [ATP]/[ADP] ratios using phosphoenolpyruvate carboxykinase. J. Biol. Chem. 258, 10464-10473.

Windmueller, H. G., and Spaeth, A. E. (1974). Uptake and metabolism of plasma glutamine by the small intestine. J. Biol. Chem. 249, 5070-5079.

Wishart, D. S., Feunang, Y. D., Marcu, A., Guo, A. C., Liang, K., Vazquez-Fresno, R., et al. (2018). HMDB 4.0: the human metabolome database for 2018. Nucleic Acids Res. 46, D608-D617.

Wong, N., Ojo, D., Yan, J., and Tang, D. (2015). PKM2 contributes to cancer metabolism. Cancer Lett. 356, 184-191. doi: 10.1016/j.canlet.2014.01.031

Wuensch, S. A., and Ray, P. D. (1997). Synthesis of citrate from phosphoenolpyruvate and acetylcarnitine by mitochondria from rabbit enterocytes: implications for lipogenesis. Comp. Biochem. Physiol. B Biochem. Mol. Biol. 118, 599-605. doi: 10.1016/s0305-0491(97)00242-3

Yamada, K., and Noguchi, T. (1999). Nutrient and hormonal regulation of pyruvate kinase gene expression. Biochem. J. 337(Pt 1), 1-11. doi: 10.1042/0264-6021: 3370001

Yang, H., and Jia, X. (2014). Safety evaluation of Se-methylselenocysteine as nutritional selenium supplement: acute toxicity, genotoxicity and subchronic toxicity. Regul. Toxicol. Pharmacol. 70, 720-727. doi: 10.1016/j.yrtph.2014.10. 014

Yang, M., and Vousden, K. H. (2016). Serine and one-carbon metabolism in cancer. Nat. Rev. Cancer 16, 650-662. doi: 10.1038/nrc.2016.81

Yang, W., and Lu, Z. (2013). Nuclear PKM2 regulates the Warburg effect. Cell Cycle 12, 3154-3158.

Yang, W., and Lu, Z. (2015). Pyruvate kinase M2 at a glance. J. Cell Sci. 128, 1655-1660. doi: $10.1242 /$ jcs. 166629

Yang, W., Zheng, Y., Xia, Y., Ji, H., Chen, X., Guo, F., et al. (2012). ERK1/2dependent phosphorylation and nuclear translocation of PKM2 promotes the Warburg effect. Nat. Cell Biol. 14, 1295-1304. doi: 10.1038/ncb 2629

Ye, D., Guan, K. L., and Xiong, Y. (2018). Metabolism, Activity, and Targeting of Dand L-2-Hydroxyglutarates. Trends Cancer 4, 151-165. doi: 10.1016/j.trecan. 2017.12.005

Yoon, S., Kim, J. G., Seo, A. N., Park, S. Y., Kim, H. J., Park, J. S., et al. (2015). Clinical implication of serine metabolism-associated enzymes in colon cancer. Oncology 89, 351-359. doi: 10.1159/000439571

You, J., Shi, X., Liang, H., Ye, J., Wang, L., Han, H., et al. (2017). Cystathioninegamma-lyase promotes process of breast cancer in association with STAT3 signaling pathway. Oncotarget 8, 65677-65686. doi: 10.18632/oncotarget.20057

Yu, L., Teoh, S. T., Ensink, E., Ogrodzinski, M. P., Yang, C., Vazquez, A. I., et al. (2019). Cysteine catabolism and the serine biosynthesis pathway support pyruvate production during pyruvate kinase knockdown in pancreatic cancer cells. Cancer Metab. 7:13.

Yu, Y. H., Chang, Y. C., Su, T. H., Nong, J. Y., Li, C. C., and Chuang, L. M. (2013). Prostaglandin reductase-3 negatively modulates adipogenesis through regulation of PPARgamma activity. J. Lipid Res. 54, 2391-2399. doi: 10.1194/ jlr.m037556

Yuan, M., McNae, I. W., Chen, Y., Blackburn, E. A., Wear, M. A., Michels, P. A. M., et al. (2018). An allostatic mechanism for M2 pyruvate kinase as an amino-acid sensor. Biochem. J. 475, 1821-1837. doi: 10.1042/bcj20180171

Yuen, C. A., Asuthkar, S., Guda, M. R., Tsung, A. J., and Velpula, K. K. (2016). Cancer stem cell molecular reprogramming of the Warburg effect in glioblastomas: a new target gleaned from an old concept. CNS Oncol. 5, 101-108. doi: 10.2217/cns-2015-0006

Zeidan, Q., and Hart, G. W. (2010). The intersections between O-GlcNAcylation and phosphorylation: implications for multiple signaling pathways. J. Cell Sci. 123, 13-22. doi: 10.1242/jcs.053678

Zelewski, M., and Swierczynski, J. (1991). Malic enzyme in human liver. Intracellular distribution, purification and properties of cytosolic isozyme. Eur. J. Biochem. 201, 339-345. doi: 10.1111/j.1432-1033.1991.tb16 291.x

Zhang, Z., Deng, X., Liu, Y., Liu, Y., Sun, L., and Chen, F. (2019). PKM2, function and expression and regulation. Cell Biosci. 9:52.

Zhao, J., Li, J., Fan, T. W. M., and Hou, S. X. (2017). Glycolytic reprogramming through PCK2 regulates tumor initiation of prostate cancer cells. Oncotarget 8, 83602-83618. doi: 10.18632/oncotarget.18787

Zhou, H. L., Zhang, R., Anand, P., Stomberski, C. T., Qian, Z., Hausladen, A., et al. (2019). Metabolic reprogramming by the S-nitroso-CoA reductase system protects against kidney injury. Nature 565, 96-100. doi: 10.1038/s41586-0180749-z

Zhou, S., Kachhap, S., and Singh, K. K. (2003). Mitochondrial impairment in p53deficient human cancer cells. Mutagenesis 18, 287-292. doi: 10.1093/mutage/ 18.3.287

Zielke, H. R., Sumbilla, C. M., Sevdalian, D. A., Hawkins, R. L., and Ozand, P. T. (1980). Lactate: a major product of glutamine metabolism by human diploid fibroblasts. J. Cell. Physiol. 104, 433-441. doi: 10.1002/jcp.1041040316

Conflict of Interest: The author declares that the research was conducted in the absence of any commercial or financial relationships that could be construed as a potential conflict of interest.

Copyright (c) 2020 Chinopoulos. This is an open-access article distributed under the terms of the Creative Commons Attribution License (CC BY). The use, distribution or reproduction in other forums is permitted, provided the original author(s) and the copyright owner(s) are credited and that the original publication in this journal is cited, in accordance with accepted academic practice. No use, distribution or reproduction is permitted which does not comply with these terms. 